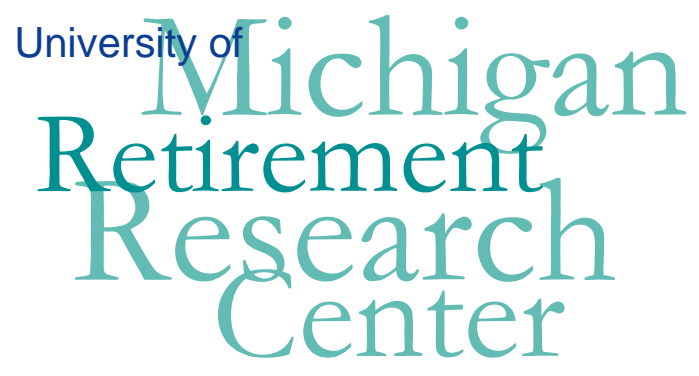

Working Paper

WP 2007-161

\title{
The Impact of Private Participation on Disability Costs: Evidence from Chile
} Estelle James, Alejandra Cox Edwards and Augusto Iglesias

\begin{tabular}{|l|l|l|l|l|l|l}
\hline $\mathrm{M}$ & $\mathrm{R}$ & Project \#: UM07-14 \\
\hline $\mathrm{R}$ & $\mathrm{C}$ \\
\hline
\end{tabular} 


\title{
The Impact of Private Participation on Disability Costs: Evidence from Chile
}

\author{
Estelle James \\ Urban Institute \\ Alejandra Cox Edwards \\ California State University, Long Beach \\ Augusto Iglesias \\ Urban Institute \\ October 2007 \\ Michigan Retirement Research Center \\ University of Michigan \\ P.O. Box 1248 \\ Ann Arbor, MI 48104 \\ http://www.mrrc.isr.umich.edu/ \\ (734) 615-0422
}

\section{Acknowledgements}

This work was supported by a grant from the Social Security Administration through the Michigan Retirement Research Center (Grant \# 10-P-98362-5-04). The findings and conclusions expressed are solely those of the author and do not represent the views of the Social Security Administration, any agency of the Federal government, or the Michigan Retirement Research Center.

\section{Regents of the University of Michigan}

Julia Donovan Darrow, Ann Arbor; Laurence B. Deitch, Bingham Farms; Olivia P. Maynard, Goodrich; Rebecca McGowan, Ann Arbor; Andrea Fischer Newman, Ann Arbor; Andrew C. Richner, Grosse Pointe Park; S. Martin Taylor, Gross Pointe Farms; Katherine E. White, Ann Arbor; Mary Sue Coleman, ex officio 


\title{
The Impact of Private Participation on Disability Costs: Evidence from Chile
}

\author{
Estelle James, Alejandra Cox Edwards and Augusto Iglesias
}

\begin{abstract}
Social security systems in many countries face problems of high and escalating disability costs. This paper analyzes how disability costs have been controlled in Chile. The disability insurance system in Chile is much less well-known than the pension part, but it is equally innovative. It differs from traditional public disability insurance in two important ways: 1) it is largely pre-funded, sufficient to cover a lifetime disability annuity and 2) the disability assessment procedure includes participation by private pension funds (AFPs) and insurance companies, who finance the benefit and have a direct pecuniary interest in controlling costs. We hypothesize that these procedures and incentives will keep system costs low, by cutting the incidence of successful disability claims. Using the Cox proportional hazard model based on a retrospective sample of new and old system affiliates (ESP 2002), we conclude that observed behavior is broadly consistent with this hypothesis. Disability hazard rates are only $20-35 \%$ as high in the new system as in the old, after controlling for other co-variates. Furthermore, analysis of mortality rates among disabled pensioners (using probit and proportional hazard models) suggests that the new system has accurately targeted those with more severe medical problems.
\end{abstract}

\section{Authors' Acknowledgements}

Estelle James is Professor Emeritus, State University of New York, Stony Brook and Consultant to the World Bank and other organizations. Alejandra Cox Edwards is Professor of Economics, California State University, Long Beach. Augusto Iglesias is Director, PrimAmerica Consultores, Santiago, Chile. We appreciate support from the Social Security Administration through the Michigan Retirement Research Center. The findings and conclusions expressed are solely those of the authors and do not represent the views of the Social Security Administration or the Michigan Retirement Research Center. Contact numbers: ejames@estellejames.com and edwards.ac@ca.rr.com. We thank the representatives of AFPs, insurance companies, the Association of AFPs and the Superintendencia of AFPs for their assistance, Juan Pablo Contreras and Janette Kawachi who helped us to organize the data for a previous version, and Ruben Castro and Pat Wiese for useful exchanges of ideas and information. 


\section{The Impact of Private Participation on Disability Costs: Evidence from Chile}

by Estelle James, Alejandra Cox Edwards and Augusto Iglesias

Social security systems in many countries face problems of high and escalating disability costs. This has been ascribed, alternatively, to demand-side factors such as unemployment rate and generosity of benefits, versus supply-side factors such as eligibility rules and assessment procedures. (See, for example, Duggan and Imberman 2006, Autor and Duggan 2006, Autor and Duggan 2003, Rupp and Stapleton 1995 and 1998, Gruber 2000, von Wachter et al 2007). Assessment procedures and the incentives they embody potentially play an important role in determining system costs. Furthermore, disability is a more subjective condition than old age, and such programs are therefore prone to errors of false positives and false negatives. The procedures used to evaluate claims can influence the balance between these two types of errors and through it the accuracy and equity of the program.

Countries that have adopted old age pension systems that include individual accounts (funded, privately managed defined contribution plans) face an additional issue - the need to integrate disability benefits into their new structure. The defined contribution system might generate reasonable replacement rates for workers who contribute throughout their lifetimes, but very low replacement rates for those who become disabled when young. Yet, if disabled people continue to receive their benefits from the traditional pay-as-you-go (PAYG) system, this will take an increasingly large percentage of total social security taxes in the future. Moreover, it may encourage workers with small accumulations to apply for disability rather than old age benefits, which will raise taxpayer costs further.

This paper analyzes how Chile, the country that pioneered individual account systems, handles disability insurance and has cut disability costs. The disability insurance system in Chile is less well-known than the old age pension part, but it is equally innovative. It differs from traditional public disability insurance in two ways: 
1) it is largely pre-funded--through the accumulation in the retirement account and later through an additional payment made when the person becomes permanently disabled, sufficient to cover a lifetime defined benefit annuity; and

2) the disability assessment procedure includes participation by private pension funds (AFPs) and life insurance companies, who finance the benefit and have a direct pecuniary interest in controlling costs and reducing adverse selection.

Survivors' insurance is handled in the same way, through a combined disability and survivors' (D\&S) fee. These fees are strikingly lower in Chile than in countries with pure public PAYG systems. The insurance fee is currently about $1 \%$ of wages, with $2 / 3$ of this - approximately .7\% of wages--for lifetime disability benefits. D\&S insurance fees are $.9 \%-1.7 \%$ of wages in other Latin American countries that adopted features of the Chilean model (AIOS 2005). For comparison, the disability cost is $1.8 \%$ of wages and running into financial difficulties in the US (covering the disabled only until normal retirement age), over 3\% in most other OECD countries and up to $10 \%$ in some European countries (US Social Security Advisory Board 2001; Andrews 1999). The age-specific inflow of newly disabled beneficiaries is also much lower in Chile. While many factors besides system incentives help account for these differentials, we argue that pre-funding and participation of private pension funds in the assessment procedure are important parts of the story.

Part I describes the Chilean procedures, using data provided to us by the Association of AFPs, and hypothesizes that the participation of private pension funds in the assessment procedure will keep system costs low, by cutting the incidence of successful disability claims. Part II tests this hypothesis, applying the Cox proportional hazard model to a recent retrospective sample of old and new system affiliates. We find that the hazard of workers becoming disability pensioners in the new system is only 20 $35 \%$ that in the old system, after controlling for age, gender, marital status and unemployment rates. Further, the new system appears to accurately target the disabled with more severe medical problems, as measured by higher mortality rates among newsystem disability pensioners. The Conclusion considers implications for other countries. 


\section{Cost Controls by Private Pension Funds in the Chilean Scheme}

\section{How disability insurance workers in Chile $^{1}$}

Disability insurance in Chile starts with the mandatory retirement accounts, to which each individual must contribute $10 \%$ of wages. This contribution is invested in the pension fund company (AFP) of his choice. Old age pensions depend on this defined contribution plus investment earnings. In contrast, if a worker becomes disabled before retiring, he receives a defined benefit. This is accomplished through the private insurance market, with government providing detailed regulations and back-up guarantees.

Specifically: Each insured worker is guaranteed a benefit that is $70 \%$ of his average wage if he is totally disabled, $50 \%$ if partially disabled, indexed to inflation. During an initial three-year period of temporary disability, this benefit is paid directly by the AFP. After the provisional period, if the worker is certified as permanently disabled, the entire lifetime benefit is funded. Part of this benefit is covered by his own retirement account. The remainder is covered by a term group insurance policy, which provides the top-up (the "additional payment") needed to finance an annuity that equals the specified defined benefit. Each AFP is required to purchase this insurance policy for its affiliates. The typical contract shares the risk: the AFP covers costs up to a ceiling and keeps most of the savings beneath that ceiling, while the insurance company takes over after the maximum rate has been reached. Survivors' insurance for workers is covered in the same way, by the same insurance policy, in exchange for a combined D\&S insurance fee that is passed on to workers by the AFP.

Thus the total future pension is fully pre-funded at the point when the individual is certified as permanently disabled - partly out of his own retirement savings and partly by the group insurance policy purchased by the AFP. The disabled worker uses these funds to purchase a lifetime annuity or a programmed withdrawal pension that follows a formula set by the regulator. ${ }^{2}$

The D\&S insurance fee is included in the general administrative charge that each worker pays the AFP. Each AFP sets its own fees and, apart from a small flat component, is required to charge all its affiliates the same percentage of their wage- 
regardless of age, gender, occupation, health status or account size. AFP fees currently average around $2.4 \%$, of which the disability insurance portion is about .7\% and the survivors insurance portion is .3\% (authors' estimates). A previous paper develops a simple model for determining the group insurance premium, taking the age-specific incidence of disability as given. It shows that, in steady state, the money in the workers' account is projected to cover about half of the total disability benefit, on average. The fee for a fully funded Chilean-type scheme will be more than that in a PAYG scheme in the short run, but less in the long run. (We are now in the medium term, with moderate advantages to the funded plan). The funded system is more sensitive to interest rate changes but less sensitive to population aging (James and Iglesias 2006).

\section{Participation by AFPs in the assessment procedure: the incentive to control costs}

In most public disability systems a government agency or body of medical experts must juggle sometimes-conflicting roles as advocate for taxpayers, protector of claimants and impartial judge and jury, in assessing disability claims. Neither civil servants nor medical experts have direct financial incentives to limit successful claims. The high disability costs in many countries have been ascribed to public gatekeepers who are generous at the taxpayers' expense, who allow governments to use disability benefits as a substitute for unemployment insurance or early retirement and in some cases accept bribes in return for applying lax standards.

Prior to 1982 Chile's disability system was like traditional publicly managed schemes in other countries. It was run on a pay-as-you-go basis, although with a deficit that was covered by the public treasury. Disability claims were assessed by a public sector Medical Commission without any private participation.. This changed when the new retirement system was introduced in 1982. Workers then in the labor force had a choice between staying in the old system or switching to the new system; most young workers switched while older workers remained. New entrants to the labor force had to join the new system. Thus, after 1982 the two systems co-existed, although the old system is gradually being phased out.

Chile's new disability system attempts to balance public gatekeepers with countervailing incentives from private AFPs to contain costs. AFPs and life insurance companies play a major role in the administration of disability benefits, including 
participating in claim assessments, bringing appeals, monitoring eligibility conditions and determining disability criteria. For any given total fee the AFP charges, lower disability costs mean more profits for the AFP. Suppose the AFP starts out with a total fee of $2.4 \%$ of the worker's wage, and an actual cost of $2 \%$, half of which is the insurance cost, thereby earning the $.4 \%$ differential as its profit. If it cuts the insurance cost to $.8 \%$ and continues charging the same market-determined fee, its profits increase by $50 \%$ ((2\%$1.8 \%) / .4 \%=50 \%$ ). AFPs are therefore highly motivated to keep disability probabilities low, and they are given a role in the evaluation procedure that allows them to pursue this goal. We argue that this procedure produces lower age-specific disability claims than would be the case in the old system.

\section{Assessment for temporary and permanent disability}

Initial claims are evaluated by 21 Regional Medical Boards, each made up of three doctors hired by the public Superintendencia of AFPs (SAFP), but financed by the AFPs. The member may present his/her own medical tests and invite his/her personal doctor to take part in the discussions (but not the vote). The AFPs and life insurance companies also have a non-voting representative--their Associations have organized a group of medical observers, who regularly attend Board meetings and monitor its work. About $60 \%$ of all claims are approved at the first assessment, for a temporary disability benefit. Three years later (or sooner, if the individual reaches the normal retirement age), the member is re-assessed. AFPs also participate in this second assessment. In 2004, 70\% of those who were provisionally disabled in 2001 came up for a second reassessment; $30 \%$ dropped out due to death, improvement or because they had learned they were ineligible for insurance and/or had a low benefit (see below). About $94 \%$ of claimants were approved as permanently disabled (Association of AFPs 2004). The additional payment to cover the cost of the annuity is put into the account of the individual at the point when he is certified as permanently disabled and insured. He receives a lifetime benefit even if he returns to work; hence work by disabled beneficiaries is not penalized, as it is in many countries. (In this sense, the Chilean disability system rewards work, as does the Chilean old age system; see Edwards and James 2006). 


\section{Appeals by AFPs and life insurance companies}

Traditional public systems usually do not allow agencies to appeal against approved claims; they only allow workers to appeal denials of disability status. And workers who appeal are, in some countries, allowed to be represented by attorneys. As a result, the appeals process invariably raises successful claims and costs. In the U.S., for example, appeals raise successful claims by 15-20 percentage points. ${ }^{3}$ In Chile, the process is more symmetrical-AFPs, life insurance companies and workers can appeal the decisions of the Regional Boards to a Central Board. The Central Medical Board is also made up of three physicians appointed and paid by the SAFP but financed by the AFPs. Some AFPs hire their own doctors to try to build strong appeals. In 2004 AFPs and life insurance companies appealed $26 \%$ of provisionally approved claims and $18 \%$ of permanent approved claims, and one-third of these appeals were successful. In the same year, workers appealed $57 \%$ of denied claims and $23 \%$ of them were successful. The number of successful appeals by AFPs and insurance companies offset the successful appeals by workers, so the net impact of appeals was 0 (Association of AFPs 2004).

\section{AFP role in shaping criteria for total and partial disability}

A Technical Commission meets periodically to determine the medical criteria for granting partial and total disability. Representatives of the AFPs and the insurance companies, as well as three public representatives, sit on this commission, with a vote. For each handicap presented by the member, the rules allot a certain percentage of disability, which are summed to produce the total degree of disability. The Medical Boards may increase this percentage discretionarily according to specified "complementary factors" in the case of older members with a low level of income, or when the member loses the ability to perform his or her normal job. If the degree of disability exceeds $67 \%$ the member is considered totally disabled, whether or not he has continued to work, and is granted a $70 \%$ defined benefit. If the degree of disability is $50-$ $67 \%$ he is partially disabled and gets a $50 \%$ defined benefit. If degree of disability is less than $50 \%$, he is not considered disabled. Among the claims that were approved in 2004, $25 \%$ were for partial disability. This proportion has been increasing over time. 


\section{Eligibility for insurance: avoiding adverse selection}

Adverse selection could potentially be a big problem in an economy like Chile's, with a high degree of informality and self-employment. A healthy worker could avoid contributing by working in the informal sector, but move to the formal sector if he develops a complaint and anticipates filing a disability claim. Self-employed individuals and independent contractors are not required to contribute to the system but may voluntarily do so if they suspect they are becoming disabled. This is more likely as subjective and chronic diagnoses for disability, such as back pain and mental illness, whose intensity and timing are difficult to establish, replace more objective and acute diagnoses such as cardiac problems. Such strategic behavior would enable disabled workers to get relatively large benefits for relatively small lifetime contributions, while healthy workers try to stay out of the system, thereby raising insurance fees for the average worker.

Workers who are approaching old age with small accounts, because they have worked in the informal sector or self-employment for part of their lives, also have a strong incentive to enter the system and apply for disability, because their defined benefit would be greater than the old age benefit based on their own accumulation. ${ }^{4}$ This would require a large "additional payment" by the AFP or insurance company. Thus, adverse selection based on size of contingent top-up as well as probability of disability may raise the rate of disability applications among contributors and insurance costs for the system as a whole, especially in countries with easy movement in and out of the informal sector.

However, insurance eligibility rules, monitoring and marketing strategies by AFPs reduce the likelihood that this will happen. AFPs market aggressively to individuals who fall into low-risk categories, by paying higher commissions to sales agents who bring them into membership; but some AFPs pay small or zero commissions for new members who are high risk or become disabled within two months of joining. This counteracts adverse selection among the self-employed.

While certification for disability depends purely on medical grounds, eligibility for the defined benefit and the top-up--which would raise costs for others--depends on recent work history. In general, an individual must have worked and contributed within the past 12 months in order to be insured and get the additional payment. ${ }^{5}$ If this 
requirement is enforced, it limits strategic behaviour, especially among workers with acute sources of disability. Poor record-keeping by public agencies in many countries, including Latin American countries in the past, has made it difficult to enforce insurance eligibility requirements. In contrast, AFPs keep the contribution records of affiliated workers and thus can ensure that they have contributed long and recently enough to be eligible for insurance. In 2004 only $60 \%$ of all successful claims at the first stage and $70 \%$ at the second stage were deemed eligible for insurance (Association of AFPs 2004). Most of the growth in disability probabilities in recent years has occurred among the uninsured-AFPs have little incentive to spend resources on questioning or appealing non-insured claims.

\section{Combating strategic behavior by monitoring the reference wage}

Another way the Chilean system discourages strategic behavior by workers with irregular contribution histories is by setting a low reference wage for such people. The reference wage used to determine the defined benefit is the simple average of earnings during the prior ten years, expressed in the price-indexed Chilean currency, the UF (Unidad de Fomento), and with a ceiling. Workers who have been in the informal sector, unemployed, or out of the labor force for part of the last ten years will have 0's averaged in and will therefore have a low reference wage and benefit, even if they are insured. ${ }^{6}$ For example: The wage replacement rate for a steady worker who becomes disabled is $70 \%$, but a worker who contributed only $60 \%$ of the last ten years would receive only $42 \%$ of his working wage $(60 \%$ of $70 \%))^{7}$ This is important because the density of contributions in Chile - that is, the portion of his working life that an average worker contributes - is about 60\% (Berstein, Larrain and Pino 2005; Arenas, Behrman and Bravo 2004; Arenas et al 2007). This downsized reference wage makes it less likely that workers with irregular work histories will try to re-enter the system to become eligible for disability insurance, and it saves money for the system if they do get back in. AFPs use their records to ensure that these rules for defining the reference wage are strictly applied, thereby diminishing adverse selection and disability costs. 


\section{Results of the claims assessment procedure and eligibility rules}

As a result of the first and second assessments, the appeals procedure and eligibility rules, only a small percentage of initial claims result in insurance-funded permanent disability benefits. Based on data from 2004-06, out of 100 claimants. $^{8}$

- About 60 are approved at the first stage

- 37 of the approved claims were deemed eligible for insurance

- 42 will be reevaluated in 3 years for permanent disability

- 40 of these will be accepted

- 28 of those approved for permanent disability will be eligible for insurance

- Successful appeals by workers, AFPs and insurance companies net out to 0 Thus, only $28 \%$ of original claimants are projected to end up permanently disabled and insured, a proportion that is quite low by international standards (in the US, for example, acceptance rates are more than double). The rest are not considered disabled or, if disabled, do not get access to the insurance top-up (or may die or improve before reaching the second assessment). Among those disabled and insured, one quarter are only partially disabled and get a 50\% benefit. Many have a reference wage that is far less than their full working wage and therefore a benefit that is far less than $70 \%$ (or $50 \%$ ) of their full working wage. A major role in containing these costs is played by the AFPs and life insurance companies, who actively participate in the assessment procedure, help set the rules, have a vested interest in enforcing them, and use their Association to keep careful track of their success.

\section{The government's minimum pension guarantee}

Underpinning these privately financed arrangements is the government's minimum pension guarantee, which sets a floor - currently $25-29 \%$ of the average wage - to disability and old age pensions. Twenty years of contributions are needed for MPG eligibility among old age pensioners, but only ten years (or even less) are needed among disability pensioners. ${ }^{9}$ If the pensioner's accumulation (including the additional payment) is not large enough to cover an annuity above the MPG level, he or she must keep the money in the account and withdraw monthly benefits equal to the MPG. When the account balance becomes zero, the government steps in to pay the pension, if the pensioner is eligible for the MPG. Presently, about half of all disabled pensioners have 
benefits at the MPG level and in one third of these cases the benefits are financed by the public treasury.

Several sub-groups of disabled already described are likely to find themselves in this situation: 1) members who are granted disability status but are not eligible for insurance because they are not current contributors; 2) insured individuals who contributed for only a fraction of their working lives and therefore have a small reference wage and pension; 3 ) insured individuals who choose programmed withdrawals and live longer than the out-dated mortality tables predict; 4) partially disabled workers who get only a $50 \%$ defined benefit; and 5) surviving widows of disabled workers. For each of these categories, policy choices reduce the cost of the private insurance but increase the cost of the public contingent liability. These costs will be small if the MPG is priceindexed (as it is, by law) and therefore falls over time relative to the average wage, but they will be large if the MPG rises with wage growth (as it has de facto over the past twenty years). Thus, the MPG serves as a safety valve for a cost-conscious private disability insurance system but its own future costs are uncertain. For further analysis of the MPG see James, Martinez and Iglesias 2006, Edwards and James 2006.

\section{Disability inflow rates in Chile vs. other countries}

We expect these procedures to lead to a low inflow of age-specific newly disabled beneficiaries relative to insured population in Chile compared with other countries and, indeed, this is the case. For example, in 1999, for age group 45-54, 2.9 per thousand members were accepted to new disabled status in Chile, compared with 7.8 per thousand people in that age group in the US and 8.6 in OECD as a whole (OECD 2003 and Table 1). Over all ages, 1 per thousand was accepted to new insured disability status in Chile in 2004, compared with 3 to 5 per thousand in the US over the past two decades (US Social Security Board of Trustees 2005; Social Security Bulletin, various years). These low incidence rates lead to low insurance fees. The disability charge is about .7\% of wages in Chile but 1.8\% (covering the disabled only until normal retirement age) in the U.S. and 3$5 \%$ in most European countries (US Social Security Advisory Board 2001; Andrews 1999). Of course, many factors besides system incentives enter into these incidence and cost differentials--in particular, the definition of disability, the existence of other programs that cover certain groups of disabled, the generosity and indexation of benefits, 
and whether they cover the worker until the normal retirement age or death. ${ }^{10}$ Also, the fact that workers have to finance part of the benefit out of their own accounts may discourage claims, especially for those with large accounts. However, it seems likely that participation of private pension funds in the assessment procedure are important parts of the story.

\section{Testing the New System Impact}

\section{The sample}

To hold all other factors constant, it is most useful to compare disability inflow rates in the new and old Chilean systems. We hypothesize these rates are lower in the new system, for all the reasons given above. To test this hypothesis, we apply the KaplanMeier survival function and Cox proportional hazard model to a recent sample survey of new and old system affiliates (EPS2002). EPS is a large retrospective survey, with about 17,000 observations, that was conducted in 2002 and is representative of the universe of people who were affiliated with the new or old systems at some point between 1982 and 2001. We know each individual's system affiliation and age in 2002, age of death, disability or old age pension (if relevant), schooling, sex and marital status. We are interested in the propensity of these affiliates to become disabled pensioners and whether this propensity is different under the new and old systems, after controlling for other factors that might affect the disability hazard.

To carry out this analysis, from this large sample we constructed a sub-sample of individuals who were born 1932-1962. We excluded individuals who were born before 1932, because of potential survival bias and memory problems. Their working years, when they would have been at risk for disability, occurred many years ago, when conditions were quite different, and their memory may be unreliable. Some members of the pre-1932 cohorts may have died before 1982, so never entered the sample frame; therefore they are not fully represented in EPS2002. Many more of these earlier cohorts died between 1982 and 2002 and, in practice, may not be fully represented in EPS2002 even though they supposedly are. Since death rates are likely to be higher for the disabled, this under-reporting of the dead may bias downward disability hazard rates, 
especially for the old system in which these older cohorts are concentrated. These problems are diminished for cohorts that were born later, whose members are less likely to have died and less likely to be underreported if they did die. Therefore we confine our main analysis to cohorts born after 1932. But we also test sensitivity to enlarging the subsample, including all who were born 1922-62. We discuss these points further below.

We focus our analysis on the hazard of disability pensioning between ages 40 and 64 , because disability pensions below age 40 are a very low probability occurrence, and eligibility stops at age 65 for men, 60 for women. Effectively, this means that we omit cohorts who were born after 1962, who were under 40 by 2002. It also means that we omit the small number of individuals who had pensioned before age 40 .

Applying these cohort cut-off criteria, we create a sub-sample consisting of 1840 individuals born 1932-62 who were old system affiliates throughout their working lives, 2988 who were new system affiliates throughout their working lives and 2890 who were old system affiliates initially but switched to new system affiliation after $1982 .{ }^{11}$ These switchers are treated as if they were in the old system sample before 1982 and the new system sample afterwards. Thus, they all appear in our analysis of new system hazards. However, since our study covers ages 40-64, they appear in our old system analysis only if they were at least 40 years old in 1982. In reality, most switchers were younger than 40 in 1982, leaving just 606 switchers to be included in our old-system sub-sample. For this purpose, we create a double identity for these 606 switchers — one in the old system prior to 1982 and one in the new system afterwards; they are identical except for system affiliation and age (they were younger when in the old system). Therefore we end up with 8324 observations, of whom $70 \%$ are in the new system (see Table 2).

Disability pensioners comprise about $2 \%$ of the total, or 172 individuals, only $1 / 3$ of them in the new system. The smaller proportion of new system disability pensioners in due, in part, to the age differentials between our new and old system sub-samples and, in part, to differential procedures and incentives; we seek to disentangle these effects.

We construct the retrospective histories of these individuals going back to age 40 in the old system, age 40 (or age in 1982, if greater than 40) in the new system. Of course, our old-system sample comes from earlier cohorts than our new-system sample. Among cohorts born before 1942, most were old-system members while among those 
born afterwards, most were in the new system. The median age when they exited our subsample (in 2002 or at age of death, pension or switching, whichever came first), is 53 for old-system members and 48 for new system members (Table 2). However, there is substantial overlap in ages between the two systems (Table 3). Most disability pensioning occurred between ages 40-59, during the 1990's, in both systems. Some old system members, but practically no new system members, started their disability pensions in the 1980's. (Table 4).

\section{Kaplan-Meier survival functions for new and old systems}

We start by examining Kaplan-Meier survival functions, separately for the new and old systems (Figure 1), for ages 40-64. This shows us the cumulative probability $\left(\mathrm{CumS}_{\text {age }_{t}}\right)$ that an individual who is a member of the "at risk group" will remain without a disability pension up to a given age, $t$. It is obtained by multiplying the single-year survival rates for all preceding ages, up to and including age t. We define the "at risk" group at a given age as all individuals who reached that age without a disability or old age pension and the hazard of dropping out as a disability pensioner is the proportion of the at-risk group who became a new disabled pensioner at that age. These are the "failures" and the rest are "survivors."

$$
\text { CumS }_{\text {age }_{t}}=\operatorname{CumS}_{{\text {age } e_{t-1}}} * S_{\text {age }_{t}}
$$

where:

Atrisk $_{40}=$ All non-pensioner affiliates at start of age 40

failures $_{40}=$ number of newly disabled at age 40

$S_{40}=$ Survives at age $40=1-\frac{\text { failure }_{40}}{\text { Atrisk }_{40}}$

Atrisk $_{41}=$ Atrisk $_{40}-$ failures $_{40}-$ dropouts $_{41}+$ newentrants $_{41}$

dropouts $_{41}=$ number at risk age 40 who become old age or early retirement

pensioners between 40 and 41

newentrants $s_{41}=$ number of new entrants to system between age 40 and 41

$$
S_{41}=1-\frac{\text { failures }_{41}}{\text { Atrisk }_{41}}
$$


The initial "at risk" group at the start of age 40 is the total number of individuals who were in the system at 40 and had not yet pensioned. Individuals who take a new disability pension during age 40 are considered a "failure" and the survival probability for age $40=1-\frac{\text { failures }_{40}}{\text { Atrisk }_{40}}$. The "at risk" group at the start of age 41 is the total number of individuals who were in the system at 41 and had not yet pensioned. This equals the number at risk at 40 - failures at 40 - dropouts for an old age pension or death during age $40+$ new labor market entrants during age 40 . The survival rate at $41=1-\left(\frac{\text { failures }_{41}}{\text { Atrisk }_{41}}\right)$ and the cumulative survival rate at $41=\operatorname{CumS}_{40} * S_{41}$. And so on.

It is immediately apparent from the K-M curve that new-system affiliates have a significantly higher probability of surviving as non-disability-pensioners than old-system affiliates. For example, by age 55, 4.9\% of old-system affiliates had become disability pensioners, against just $1.6 \%$ of new system affiliates. We proceed to estimate the Cox proportional hazard model, which allows us to control for other factors and to establish whether these differences are statistically significant.

\section{Cox proportional hazard model}

The Cox proportional hazard model estimates a baseline hazard function and the impact of co-variates on this hazard. It enables us to estimate age-specific hazards and the statistical significance of differences due to co-variates. It is based on the assumption that the hazard, $\mathrm{h}(\mathrm{t})$ (defined as the proportion of the population at risk that becomes a newly disabled pensioner at age $\mathrm{t}$ ), is:

$$
\mathrm{h}(\mathrm{t})=\mathrm{e}^{\mathrm{Xi \beta}} \mathrm{h}_{0}(\mathrm{t})
$$

where:

$\mathrm{h}(\mathrm{t})$ is the hazard, given the values of co-variates

$\mathrm{h}_{0}(\mathrm{t})$ is the baseline hazard, setting co-variates to zero

$\mathrm{X}_{\mathrm{i}}$ is a vector of covariates

$\beta$ is a vector of parameters to be estimated.

Dividing both sides of the equation by $\mathrm{h}_{0}(\mathrm{t})$ we obtain

$$
\left.h(t) / h_{0}(t)\right)=e^{X i \beta}
$$


That is, the model assumes that the effect of $\mathrm{Xi} \beta$ is proportional over all ages covered by the baseline hazard, hence the term proportional hazard function. Our main object is to measure the impact of the co-variate "new system," which we represent by a dummy variable equal to 1 for those affiliated to the new system. In other words, we want to test the null hypothesis that individuals of the same age have the same disability hazard in the two systems. A $\beta$ different from zero (or an exponentiated $\beta$ different from 1) would lead us to reject this hypothesis. We control for other co-variates such as unemployment rate and years of education, that may have direct effects on the hazard of disability and may be correlated with new system. In each case, estimated coefficients give the amount by which the baseline hazard must be multiplied to obtain the newsystem hazard.

A proportional effect over all ages would imply that the ratio of hazards with and without co-variates is constant for all ages. Initial estimates of this effect for our data indicated that the proportionality assumption does not hold for the entire baseline.

Therefore, we changed the model specification, splitting the hazard into five sections (40$44,45-49,50-54,55-59$ and $60-64)$ to make the proportionality rule applicable over preestablished sections. In practice this means that instead of estimating one coefficient for the effect of new system and unemployment rate we estimate five coefficients, one for each section of the baseline hazard.

Tests further showed that disability hazards vary by sex and marital status, so we estimate the Cox model stratified by these two variables. In other words, we allow for differences in the baseline (old-system) hazard between men and women, married and singles, while holding the new system covariate at zero and setting the unemployment rate at $10 \%$, which is about average for the period. The estimated baseline hazards between ages 40-64 are lower for women than men and for married over single individuals (Figure 2). For example, for married women at age 48 the single-year old system hazard is . $19 \%$, while for married men it is .22\% and for single men .82\%. Baseline hazards in the 61-64 range are zero for women, since disability pensioning is ruled out after normal retirement age, which is 60 for women, 65 for men. Baseline hazards generally increase with age and peak at 5-year intervals (ages 50, 55, 60) in the old system. 


\section{The new system impact}

As expected, the exponentiated coefficients for the "new system" dummies are far smaller than one and significant at the $1 \%$ level or less in all the age ranges between 40 and 59. The coefficient is marginally significant (tested for men only) at ages 60-64 (Table 5, col. 1). Specifically, the new system hazard ranges from $49 \%$ that of the old system in the $60-64$ age range to $21 \%$ in the $45-49$ age range, with coefficients for the other age ranges in-between. Over most ages, workers in the new system are only 21$35 \%$ as likely to start a disability pension as they were in the old system. Figure 3 compares the old system (baseline) hazard and the new system hazard (baseline*estimated coefficients for each age range) for married men.

To obtain the Cox model survival function we calculate (1-hazard rate) cumulatively for the old system and (1-baseline hazard*estimated coefficient) for the new system, separately for married and single men and women (holding the other co-variates constant). As expected, in each case the estimated new-system survival functions are far above the old system estimates, because the estimated hazards for the new system are one-third to one-fifth those applicable to the old system. Although the single-age hazard rates become closer after age 60 , the cumulative survival function remains higher in the new system through age 65 , because of the larger number of survivals from earlier ages (Figures 4). These results are consistent with the hypothesis that the assessment procedure in the new system has had a strong negative impact on the rate of successful disability claims, compared with the old public disability insurance system

\section{What else could be causing these differential disability rates?}

Old and new system affiliates and pensioners come from different cohorts, span different time periods and many other factors were changing over this time. In general, old system affiliates were concentrated in cohorts born 1932-46 while most new system affiliates were born 1947-62. To what extent do time-specific demand-side factors account for the estimated change in disability hazard rates, rather than the supply-side factors that we emphasize? One such factor, changing unemployment rates, has been much-discussed in the US and international context (see Duggan and Imberman 2006, Autor and Duggan 2006, Autor and Duggan 2003, Rupp and Stapleton 1995 and 1998, Gruber 2000, von Wachter 2007). Changing level of education may be more important in 
the Chilean than the US context. We also examine the possible impact of changing eligibility rules and, relatedly, selection bias, as individuals who thought they were likely to file a disability claim stayed in the old system instead of switching into the new system. Finally, we test for sensitivity to survival bias.

Changing unemployment rates. It is often observed that disability claims rise during periods of unemployment, as individuals lose their jobs, can't find new ones and may try to avail themselves of disability benefits. Then, if unemployment rates were higher during earlier periods, this could help explain the higher disability rates observed for the old system.

We were able to disentangle the effects of new system and unemployment for two reasons: First, there is a fair degree of overlap in the years at risk and years of pensioning of old and new system affiliates, albeit at differing ages. Most time occurred in the 1980's and 1990's and most pensioning took place in the 1990's, for both systems (see Tables 3 and 4). Additionally, the Chilean economy went through cyclical upturns and downturns both before and after the reform. Unemployment was low through the 1960's, reaching $3 \%$ in 1973 , then rose sharply to $23 \%$ by 1982 , during a period of economic chaos and hyper-inflation. Post-reform, the economy went through a period of prolonged growth during which unemployment fell to $6 \%$ by 1995 but then rose during a cyclical downturn, reaching $14 \%$ by 2002 . The existence of a complete business cycle during the 1980's and 1990's is important because it reduces the correlation between the reform and unemployment rates.

In earlier work on old age pension probabilities, we found that age-specific probabilities of pensioning rose during periods of high unemployment — but this did not change the reform effect (Edwards and James 1995). That is exactly what we found here, for disability pensioning. Individuals at risk in periods of higher unemployment have a larger hazard of becoming a disability pensioner. Specifically, in our main specification (col. 1) this probability rises 5-9 percentage points for each one percentage point increase in the unemployment rate for individuals in their 50's. (But in another specification, which includes older cohorts who worked in earlier years, the unemployment rate becomes insignificant; apparently this variable is highly sensitive to choice of cohorts and time period.) However, the new system effect barely changes when unemployment is in 
the equation--in fact, it become stronger for some ages (compare columns 1 and 2 in Table 5).

Level of education. Individuals with more education might be less likely to file for disability, as their income from work is higher, their accounts larger so gains from disability insurance smaller in the new system and their jobs might be more amenable to avoiding disability. Average education levels rose rapidly over the past three decades in Chile, as the modal schooling level increased from primary to completed secondary and many Chileans acquired some higher education. Yet, when we entered person's years of education or secondary degree into the hazard model, it was never significant and did not change the reform effect. Our regressions in Table 5 therefore do not show level of education as a co-variate.

Job safety and general health conditions. On average, jobs for new-system affiliates may be safer than jobs for old-system affiliates and general health conditions may have improved, as a result of broader economic growth and its allocation to health and safety. This might reduce disability inflow rates in the new system. While job accidents are covered under a separate program from the general disability program under discussion in this paper, no such distinction was made in the EPS data, so this potential explanation remains. Moving in the opposite direction, the definition of disability has evolved to include mental as well as physical health, and the former constitute an increasing proportion of the total, which might increase the disability hazard in the new system. We do not have a variable that captures these changes on a year-to-year basis in our regressions. However, if improved job safety and health is the explanation, we might expect the new-system advantage to increase when we shift our sample to include cohorts further back in time--born after 1922 rather than 1932 - but we find that the opposite happens (see col. 4, Table 5).

New eligibility rules and selection bias. In the new system, to be covered by D\&S insurance a must have contributed during the last 12 months and also paid at least 6 contributions in the year immediately preceding the last registered contribution. In the old system, prerequisites are different. For example, in the SSS (the largest program), workers need to have at least 50 weeks of contributions and a density of contributions over the entire membership period of $50 \%$ or more. In the Caja de Empleados 
Particulares (the second largest program), eligible workers must have contributed for at least 3 years, including at least one contribution during the last 24 months. In the Caja de Empleados Públicos, the requisite is to have at least 10 years of contributions. In other words, in the new system younger workers with fewer years of contributions can qualify for disability pensions more easily than in the old system, while older workers who fulfilled the requirements for the old system in the distant past, but have worked less in the immediate past, could qualify more readily in the old system. However, we found disability rates to be lower for all age groups, 40-59 and even beyond, so new differential eligibility conditions do not appear to account for our results. ${ }^{12}$

Perhaps more important, asserted emplooyment from the distant past would be harder for officials to contradict in the old system. The new system placed a greater emphasis on the recent past, which was more readily verifiable, thereby making it easier for AFPs to present evidence that workers were ineligible for insurance.

Also, self-selection bias might have been at work. In 1982, older workers who thought that they were at high risk of applying for disability might have stayed in the old system, because they were uncertain how disability determinations would be made in the new system and whether they would meet the new eligibility requirements. This would have produced a higher incidence of disability in the old system in the mid-1980's because workers with higher propensities selected the old system, not because of declines in propensities in the new system. In fact, all the disability pensioning that took place prior to 1987 was in the old system. Therefore, we reran the Cox model, excluding all observations at risk and disability pensions that began between 1982-87, the period when selection based on disability propensities would have taken place. The new system impact remained significantly strong, except for ages 40-44 (col. 3, Table 5). ${ }^{13}$

Survival bias. Given the retrospective nature of the EPS survey, we faced a potentially severe problem of survival bias. The survey is supposed to be representative of the universe of affiliates in the new and old systems between 1982 and 2001. Even affiliates who were dead by 2001 are included. But affiliates who died before 1982 were not included. If an old-system affiliate who was not pensioned died, say, at the age of 48 in 1980, he would not be covered by the sample frame, although he was really part of the 
at-risk group in the old system between ages 40 and 48 . This omission understates the size of the at-risk group and therefore overstates the hazard rate in the old system.

However, the bigger bias goes in the opposite direction. An individual who became disabled at age 40 in 1972 and died at age 48 in 1980 would not be covered by this survey, and this would understate the size of the disability hazard for the old system. Because disabled pensioners are likely to have higher death rates than non-disabled, the proportionate omission of the disabled due to death before 1982 probably exceeds the proportionate omission of non-disabled, and therefore understates the size of the disability hazard in the old system (see von Wachter et al for U.S. data on relative mortality rates of disability pensioners and others). ${ }^{14}$

Survival bias is compounded by the possibility that affiliates who died after 1982 may have been undercounted, as a result of practical difficulties in getting information about them in 2002. To test this possibility, we formulated an expectation of how many dead affiliates should have been included in the sample, based on mortality tables (RV98) from Chile, and compared this with the reported dead observations. These reported/expected $(\mathrm{R} / \mathrm{E})$ ratios and expected minus reported $(=$ missing) dead proportions for the 1922-31 and 1932-41 cohorts are presented in Table $6 .^{15}$

These calculations are straightforward, based on official mortality tables, for all affiliates. However, for disabled pensioners they are very sensitive to assumptions about their relative expected death rate, since this is highly uncertain. If the true mortality rates of the disabled are similar to those of other affiliates, the dead disabled do not appear to be underreported. But if their true mortality rates are double those of other affiliates, the estimated missing deaths are large, consistent with our fear that disability hazards may have been understated as a result of survival bias. The estimated understatement of deaths in this case is $15 \%$ of total disabled for the $1922-31$ cohorts versus $7 \%$ for the $1932-41$ cohorts.

We can also use this methodology to get a crude estimate of the number of disabled in these cohorts who died before 1982 and therefore never appeared in the sample frame. ${ }^{16}$ Using the same assumptions, the estimated number of individuals cohort who became disabled and died before 1982, as a proportion of those who were reported as disabled in 1982 , is $10 \%$ for the $1922-31$ cohorts versus $2 \%$ for the $1932-41$ cohorts. 
This leads us to conclude that the problem of survival bias among the disabled is uncertain but might be large, and the number of missing people would be especially large if we include cohorts born close to 1922, for whom deaths were more likely. This bias would understate the hazard of becoming disabled, especially in the old system, whose members tend to be older, therefore more likely to have died. It would understate the gain from the new system. Survival bias may be even greater than we have estimated, if higher mortality rates apply to earlier cohorts, because they did not benefit from better health and mortality improvements that applied to later cohorts.

To minimize survival bias we cut off the cohorts included in the main analysis at birth year 1932, but we also show results including birth years 1922-31 (Table 5, col. 4). If survival bias is very great for older cohorts, inclusion of the 1922-31 cohorts might reduce reported disability for the old system and eliminate the reform effect. Indeed, baseline hazards and new-system effects obtained from the 1922-62 cohorts sample are lower than those obtained from the 1932-62 cohort sample, suggesting that survival bias may be present, which we mitigate by restricting our sample to the 1932-62 cohorts. However, the impact of the reform remains large and highly significant--a cut of about $60-70 \%$ at the $1 \%$ significance level or better for ages $45-59$ and marginally significant for ages 40-44 (col. 4, Table 5).

On balance, it does not seem that any of these alternative explanations could account for the consistently large estimated difference between the hazard of disability in the old and new systems. The estimated proportional differences between the old and new systems in Chile are roughly similar to the observed differences in incidence between Chile and other countries with traditional systems. They are also similar to the difference in observed stock of disability pensioners relative to old age pensioners in the new and old systems in Chile. ${ }^{17}$ These data are strongly consistent with our hypothesis that assessment procedures in the new system, including participation of private AFPs and insurance companies, cut the incidence of disability claims substantially.

\section{Mortality rates in the new and old systems as an indicator of system accuracy}

We would also like to know if these cuts are made accurately — that is, if the truly disabled are targeted. We use comparative mortality rates among those who pensioned 
after 1982 in the new and old systems as a partial test of accuracy (see von Wachter et al 2007 for use of mortality rates as a partial test of accuracy in the US system). ${ }^{18}$

If both systems had the same degree of accuracy, we might expect to find lower aggregate mortality rates among new system pensioners. New system members are younger, healthier, their illnesses are more likely to be psychiatric, and if pensioned this was likely to be more recent, therefore with shorter periods of exposure to the disability - all of which would lead to lower mortality rates. ${ }^{19}$ However, if the new system targets accurately as it cuts approved claims, it has denied the less disabled so this would raise mortality rates among its approved disabled pensioners. Therefore, if mortality rates are the same in the two systems, we take this as evidence that the new system has targeted benefits to the more disabled, and if mortality rates have increased in the new system this inference is even stronger.

We use probit and proportional hazard models to estimate the probabilities of death by 2002 of non-disabled affiliates versus disabled pensioners in the old and new systems, controlling for age, gender and years of education. We present these results with the caveat that they should be regarded as preliminary since the number of dead disability pensioners is very small. Nevertheless, the effects are statistically significant and consistent, using both approaches.

Not surprisingly, the probits show that the disabled have a $(10 \%)$ higher probability of death by 2002 than the non-disabled. Every year of age increases the probability of death, women have lower mortality rates than men and more education means lower death rates. We handle survivor bias by confining the analysis to those who pensioned after 1982 and by controlling for years of exposure as a disabled pensioner. Those who pensioned after 1986 are less likely to have died by 2002 than the others because they have fewer years of exposure. ${ }^{20}$ These effects are all significant at the $5 \%$ level or less (Table 7).

Most important for our purposes, the dummy variable for new-system disability pensioner has a large (13\%) positive coefficient, significant at less than the $1 \%$ level, after controlling for these other factors. The new-system coefficient is even larger (18\%) when we run the same regression for men only. New-system disability pensioners are more likely to have died by 2002 than old-system disability pensioners. 
To investigate this issue further, we develop Kaplan-Meier survival curves by age and Cox proportional hazard regressions of the hazard of dying, by year of exposure to the disability pensioner state. In this case, those "at risk' are all disability pensioners (disabled) or all other affiliates (nondisabled), the "failures" are those who die and the "survivors" are those who live. It turns out that, in the old system, age-specific KaplanMeier survival probabilities are practically the same for disability pensioners and other affiliates. Apparently "disability" does not target those with higher expected mortality rates in the old system. In contrast, a wide disparity opens up between survival rates of disabled and other affiliates in the new system; apparently the new system accounts for the entire positive effect on mortality of "disabled" in the probit above. Survival for the non-disabled increases in the new system compared with the old system, as we expected due to health improvements for later cohorts. However, survival for disabled pensioners drops dramatically (Figure 5). The Cox model shows that the hazard of dying within 3 years of disability pensioning is the same for the two systems, but the hazard of dying within the next 12 years is much greater for the new system, implying far lower survival probabilities (Table 8 and Figures 6 and 7).

Thus, in addition to reducing the incidence of successful disability claims, the new system seems to accurately target those individuals with the most severe medical problems, in the sense that they have much higher mortality rates than disability pensioners in the old system or non-disabled affiliates in the new system.

\section{What Can Other Countries Learn from Chile?}

Countries around the world are faced with rising costs of old age security programs. In many countries, disability expenditures are a high proportion of total social security costs and have been rising even faster than old age expenditures.

The Chilean system for disability insurance has two innovative features that help to contain costs: it is pre-funded and it utilizes private pecuniary incentives and procedures to dampen successful claims. Pre-funding in Chile takes place in two stages: first, building the retirement accounts through the worker's career and second, using an "additional payment" when the person becomes disabled to enable the purchase of a 
lifetime defined benefit. Use of workers' own retirement accounts reduces their incentive to apply for disability, particularly if their accounts are large relative to the capital needed for the disability annuity. AFPs charge an insurance fee that covers the cost of the "additional payment" and have an incentive to keep the cost low by controlling successful claims.

The assessment process includes participation by private AFPs and insurance companies and enables them to pursue this objective. We hypothesize that the pressure they create toward strict application of the rules and their right to appeal initial evaluations have the effect of reducing the incidence of approved disability cases. Our calculations of hazard and survival rates, using the Cox proportional hazard model and a retrospective data set of new and old system affiliates (EPS 2002) show significantly lower hazards of becoming disability pensioners in the new system. These hazards are cut by $65-80 \%$, compared with the old system. This is consistent with lower observed agespecific incidence of disability and disability insurance fees in Chile as compared with publicly managed systems in other countries. Comparisons of mortality rates among new and old system disability pensioners suggest that this reduction in disability hazard is achieved while targeting those with the most severe medical conditions.

Does this mean that Chile is doing the right thing? That depends. It has cut costs, apparently in a reasonably accurate way, but we don't know whether it has picked the "right" mix of benefits versus costs, false positives versus false negatives, and pension size versus incidence. Disability is hard to define and probably consists of a continuum rather than an on-off switch. Value judgments are involved in where to draw the line and with which trade-offs. The very low hazard rates in Chile's new system suggest it has chosen to minimize type 1 errors (false positives) at the possible expense of more type 2 errors (false negatives), while the old system made the opposite choice. Low private costs may eventually spill over into higher public costs via the MPG, which sets a pension floor using looser criteria. Some societies might wish to grant disability benefits more liberally, even though this will cost more and may involve more false positives. Or, for a given outlay, they might wish to pay lower benefits to a higher proportion of claimants.

Other countries, however, already consider their current disability hazard rates and costs excessive, in the sense that they impose heavy burdens on non-disabled 
workers. They might with to reduce these costs by introducing elements of competitive market provision and assessment. Even if they continue to rely on public management and finance, it might be possible to mimic some elements of the Chilean process involving countervailing force. For example, the public agency responsible for the program could be given the right to appeal approved cases, or to oppose claimants' appeals represented by lawyers who have a financial incentive to win their cases. (See similar recommendations by the US Social Security Advisory Board 2001 and Autor and Duggan 2006). This would increase the probability that both sides would be forcefully presented, which might save money and lead to greater accuracy at the same time. 
Table 1: Inflow to disability benefit status, Chile vs. US and OECD, 1999

(new inflow, per thousand in insured population)

\begin{tabular}{|l|l|l|l|l|l|}
\hline Age group & $\mathbf{2 0 - 3 4}$ & $\mathbf{3 5 - 4 4}$ & $\mathbf{4 5 - 5 4}$ & $\mathbf{5 5 - 5 9}$ & $\mathbf{6 0 - 6 4}$ \\
\hline Chile & .2 & .9 & 2.9 & 7.2 & 12.3 \\
\hline US & 2.7 & 4.5 & 7.8 & 13.9 & 12.8 \\
\hline OECD & 2.3 & 4.2 & 8.6 & 14.9 & 14.1 \\
\hline
\end{tabular}

Source: OECD data from OECD (2003), p. 81

Chilean data calculated by authors from claims and assessment data supplied by Association of AFPs, contributor and member data supplied by SAFP. Only disabled who are insured are included here-in 1999 this was about $70 \%$ of those who were granted disabled status in Chile. Inflow to temporary disability status is given; inflow to permanent disability status would be about $75 \%$ as large, depending on age. Ratios are given as $\%$ of $[($ members + contributors $) / 2]$ since insured population includes some affiliates who are not currently contributing.

OECD numbers are newly disabled beneficiaries as \% of (population in the relevant age group, minus the stock of people in that age group who are already on disability benefits). The denominator includes some people who are not eligible for insurance. If this definition were used for Chile, Chile's disability inflow rate would be much lower than given here. 
Table 2: Sub-sample composition by old and new systems and age

\begin{tabular}{|c|c|c|c|c|c|c|}
\hline & \multicolumn{3}{|c|}{ Number of observations } & \multicolumn{3}{c|}{ Median age when exit sample* } \\
\hline Affiliation & $\begin{array}{c}\text { Non- } \\
\text { switcher }\end{array}$ & Switcher & All & $\begin{array}{c}\text { Non- } \\
\text { switcher }\end{array}$ & Switcher & All \\
\hline $\begin{array}{c}\text { Old } \\
\text { System }\end{array}$ & 1,840 & 606 & 2,446 & 57 & $44^{* *}$ & 52.5 \\
\hline $\begin{array}{c}\text { New } \\
\text { System }\end{array}$ & 2,988 & 2,890 & 5,878 & 45 & 51 & 48 \\
\hline Total & 4,828 & 3,496 & 8,324 & 48 & 50 & 49 \\
\hline
\end{tabular}

* in 2002 or year of pension or death

**median age in 1982, when they switched

Table 3: Sub-sample composition by birth cohort

\begin{tabular}{|c|c|c|c|c|c|c|c|}
\hline $\begin{array}{c}\text { Year of } \\
\text { birth }\end{array}$ & $\begin{array}{c}\text { Age- } \\
\mathbf{1 9 8 2}\end{array}$ & $\begin{array}{c}\text { Age- } \\
\mathbf{2 0 0 2}\end{array}$ & $\begin{array}{c}\text { Ages } \\
\text { included }\end{array}$ & $\begin{array}{c}\text { Years } \\
\text { included }\end{array}$ & $\begin{array}{c}\text { Old- } \\
\text { system }\end{array}$ & $\begin{array}{c}\text { New- } \\
\text { system }\end{array}$ & Total \\
\hline $1932-36$ & $46-50$ & $66-70$ & $46-70$ & $1972-2000$ & 671 & 272 & 943 \\
\hline $1937-41$ & $41-44$ & $61-65$ & $41-65$ & $1978-2001$ & 768 & 464 & 1,232 \\
\hline $1942-46$ & $36-40$ & $56-60$ & $40-60$ & $1982-2002$ & 426 & 687 & 1,113 \\
\hline $1947-51$ & $31-35$ & $51-55$ & $40-55$ & $1987-2002$ & 263 & 985 & 1,248 \\
\hline $1952-56$ & $26-30$ & $46-50$ & $40-50$ & $1992-2002$ & 174 & 1,287 & 1,461 \\
\hline $1957-62$ & $20-25$ & $40-45$ & $40-45$ & $1997-2002$ & 144 & 2,183 & 2,327 \\
\hline $1932-62$ & & & & & 2,446 & 5,878 & 8,324 \\
\hline
\end{tabular}

Table 4: Sub-sample of disability pensioners

\begin{tabular}{|c|c|c|c|c|c|c|c|c|c|c|c|}
\hline $\begin{array}{c}\text { Birth } \\
\text { year }\end{array}$ & Old & New & Total & $\begin{array}{c}\text { Pension } \\
\text { year }\end{array}$ & Old & New & Total & $\begin{array}{c}\text { Pension } \\
\text { age }\end{array}$ & Old & New & Total \\
\hline $\mathbf{1 9 3 2 - 3 6}$ & 35 & 5 & 40 & $\mathbf{1 9 7 9 - 8 1}$ & 10 & 0 & 10 & $\mathbf{4 0 - 4 4}$ & 16 & 12 & 28 \\
\hline $\mathbf{1 9 3 7 - 4 1}$ & 34 & 13 & 47 & $\mathbf{1 9 8 2 - 8 6}$ & 17 & 0 & 17 & $\mathbf{4 5 - 4 9}$ & 24 & 10 & 34 \\
\hline $\mathbf{1 9 4 2 - 4 6}$ & 28 & 14 & 42 & $\mathbf{1 9 8 7 - 9 1}$ & 21 & 4 & 25 & $\mathbf{5 0 - 5 4}$ & 30 & 15 & 45 \\
\hline $\mathbf{1 9 4 7 - 5 1}$ & 14 & 11 & 25 & $\mathbf{1 9 9 2 - 9 6}$ & 24 & 15 & 39 & $\mathbf{5 5 - 5 9}$ & 30 & 11 & 41 \\
\hline $\mathbf{1 9 5 2 - 5 6}$ & 4 & 12 & 16 & $\mathbf{1 9 9 7 - 0 1}$ & 38 & 31 & 69 & $\mathbf{6 0 - 6 4}$ & 16 & 8 & 24 \\
\hline $\mathbf{1 9 5 7 - 6 2}$ & 1 & 1 & 2 & $\mathbf{2 0 0 2}$ & 6 & 6 & 12 & & & & \\
\hline $\mathbf{1 9 3 2 - 6 2}$ & 116 & 56 & 172 & $\mathbf{1 9 7 9 - 0 2}$ & 116 & 56 & 172 & $\mathbf{4 0 - 6 4}$ & 116 & 56 & 172 \\
\hline
\end{tabular}




\section{Table 5: Estimates of Determinants of Hazard of Disability Pension}

(Cox Proportional Hazard Stratified by Sex and Marital Status; numbers given are hazard ratios relative to baseline)

\begin{tabular}{|c|c|c|c|c|}
\hline $\begin{array}{l}\text { Covariate: Segment of the } \\
\text { hazard over which effect applies }\end{array}$ & $\begin{array}{l}1932-62 \\
\text { cohorts }\end{array}$ & $\begin{array}{l}1932-62 \\
\text { cohorts }\end{array}$ & $\begin{array}{l}\text { Exclude } \\
1982-87\end{array}$ & $\begin{array}{l}1922-62 \\
\text { cohorts }\end{array}$ \\
\hline New System:Age 40 to 44 & $\begin{array}{c}.355 \\
(-2.71)^{*}\end{array}$ & $\begin{array}{r}.337 \\
(-2.88)^{*}\end{array}$ & $\begin{array}{c}.579 \\
(-1.24)\end{array}$ & $\begin{array}{c}.497 \\
(-1.83)^{\star \star \star}\end{array}$ \\
\hline Age 45 to 49 & $\begin{array}{c}.21 \\
(-4.12)^{*}\end{array}$ & $\begin{array}{r}.213 \\
(-4.1)^{*}\end{array}$ & $\begin{array}{c}.145 \\
(-4.41)^{*}\end{array}$ & $\begin{array}{c}.300 \\
(-3.24)^{*}\end{array}$ \\
\hline Age 50 to 54 & $\begin{array}{l}.325 \\
(-3.5)^{*}\end{array}$ & $\begin{array}{r}.307 \\
(-3.71)^{*}\end{array}$ & $\begin{array}{c}.368 \\
(-2.64)^{*}\end{array}$ & $\begin{array}{c}.383 \\
(-3.14)^{*}\end{array}$ \\
\hline Age 55 to 59 & $\begin{array}{c}.296 \\
(-3.23) *\end{array}$ & $\begin{array}{r}.317 \\
(-3.25)^{*}\end{array}$ & $\begin{array}{c}.299 \\
(-3.18)^{*}\end{array}$ & $\begin{array}{c}.397 \\
(-2.87)^{\star}\end{array}$ \\
\hline Males -Age 60 to 64 & $\begin{array}{c}.493 \\
(-1.63)^{* * *}\end{array}$ & $\begin{array}{r}.553 \\
(-1.33) \\
\end{array}$ & $\begin{array}{c}.493 \\
(-1.63)^{\star \star \star}\end{array}$ & $\begin{array}{c}.638 \\
(-1.24) \\
\end{array}$ \\
\hline Unemployment: Age 50-54 & $\begin{array}{c}1.054 \\
(1.84)^{* * *}\end{array}$ & & $\begin{array}{l}1.111 \\
(1.99)^{\star *}\end{array}$ & $\begin{array}{l}1.010 \\
(0.42)\end{array}$ \\
\hline Age 55-59 & $\begin{array}{c}1.093 \\
(1.98)^{* *}\end{array}$ & & $\begin{array}{c}1.094 \\
(1.98)^{\star *}\end{array}$ & $\begin{array}{c}0.980 \\
(-0.87)\end{array}$ \\
\hline \#obs & 8324 & 8324 & 8217 & 9623 \\
\hline
\end{tabular}

* $\quad$ significant at $1 \%$ level or less

** significant at greater than $1 \%$ but less than $5 \%$ level

*** marginally significant at less than $10 \%$ level

Notes: Baseline differs by sex and marital status, but impact of co-variates relative to baseline is same for all. Numbers in parentheses are z-statistics. 
Table 6: Estimations of survival bias

A. Expected deaths by 2002, as \% of number alive in 1982, by cohorts in sample

\begin{tabular}{|l|l|l|l|l|l|l|}
\hline $\begin{array}{l}\text { Cohort } \\
\text { birth year }\end{array}$ & $\begin{array}{l}\text { Year } \\
\text { when 40 }\end{array}$ & $\begin{array}{l}\text { Age in } \\
\mathbf{1 9 8 2}\end{array}$ & $\begin{array}{l}\text { Age in } \\
\mathbf{2 0 0 2}\end{array}$ & $\begin{array}{l}\text { Expected } \\
\text { deaths-M }\end{array}$ & $\begin{array}{l}\text { Expected } \\
\text { deaths-F }\end{array}$ & $\begin{array}{l}\text { Expected } \\
\text { deaths-av. }\end{array}$ \\
\hline 1922 & 1962 & 60 & 80 & $41 \%$ & $27 \%$ & $35 \%$ \\
\hline 1932 & 1972 & 50 & 70 & $18 \%$ & $10 \%$ & $15 \%$ \\
\hline 1942 & 1982 & 40 & 50 & $9 \%$ & $4 \%$ & $7 \%$ \\
\hline
\end{tabular}

B. Expected vs. actual deaths, 1982-2002, as \% of number alive in 1982, by cohorts

\begin{tabular}{|l|l|l|l|l|l|l|}
\hline $\begin{array}{l}\text { Cohort } \\
\text { group }\end{array}$ & $\begin{array}{l}\text { Expected } \\
\text { deaths- } \\
\text { affiliates }\end{array}$ & $\begin{array}{l}\text { Reported } \\
\text { deaths- } \\
\text { affiliates }\end{array}$ & $\begin{array}{l}\text { Reported } \\
\text { deaths- } \\
\text { disabled }\end{array}$ & $\begin{array}{l}\text { R/E- } \\
\text { affiliates }\end{array}$ & $\begin{array}{l}\text { R/E- } \\
\text { disabled }\end{array}$ & $\begin{array}{l}\text { Missing } \\
\text { dead } \\
\text { disabled }\end{array}$ \\
\hline $1922-31$ & $25 \%$ & $21 \%$ & $35 \%$ & $84 \%$ & $70 \%$ & $15 \%$ \\
\hline $1932-41$ & $11 \%$ & $9 \%$ & $15 \%$ & $82 \%$ & $68 \%$ & $7 \%$ \\
\hline
\end{tabular}

C. Estimates of pre-1982 deaths lost to sample frame

\begin{tabular}{|l|l|l|l|}
\hline Cohorts & $\begin{array}{l}\text { \% affiliates alive at } \\
\mathbf{4 0} \text { who were dead } \\
\text { by } \mathbf{1 9 8 2}\end{array}$ & $\begin{array}{l}\text { \% disabled at } \mathbf{4 0} \\
\text { who were dead by } \\
\mathbf{1 9 8 2}\end{array}$ & $\begin{array}{l}\text { \% disabled before } \\
\mathbf{1 9 8 2} \text { who were lost } \\
\text { to sample frame }\end{array}$ \\
\hline 1922 & $7 \%$ & $14 \%$ & $16 \%$ \\
\hline 1932 & $2 \%$ & $4 \%$ & $4 \%$ \\
\hline $1922-31$ & $4 \%$ & $9 \%$ & $10 \%$ \\
\hline $1932-41$ & $1 \%$ & $2 \%$ & $2 \%$ \\
\hline
\end{tabular}

Notes: Expected deaths in Panel A are based on RV98, for the given age groups. This shows the percentage of men and women ( $\mathrm{M}$ and $\mathrm{W})$ in each cohort who were alive in 1982 who were expected to be dead by 2002. In computing the average, men are weighted $60 \%$, which is their representation in our sample.

Panel B gives reported deaths for affiliates and disability pensioners by cohort groups. Expected deaths for affiliates in these same groups are obtained by taking averages of the relevant single cohort numbers in Panel A. Expected deaths among the disabled might be much more, because of higher death rates, but less because they acquired disability status only part of the way through the period 1982-2002. We show results if expected death rates for the disabled were twice as large as for affiliates as a whole. R/E gives reported/expected deaths for disabled, subject to this assumption. Missing dead disabled in the last column $=(\mathrm{E}-\mathrm{R}$ deaths of disabled $) /$ total reported disabled pensioners during 1982-2002. Missing death would be smaller if expected deaths were smaller.

Estimates of pre-1982 deaths from age 40 lost to sample frame, in Panel C, are based on 20 and 10-year survival rates, respectively, for 1922 and 1932 cohorts. Death rate for disabled is assumed to be double that for affiliates, as above. For last column, estimated deaths among disabled prior to 1982 are given as \% of disabled from this cohort who are still alive in 1982. Although number of missing deaths is sensitive to assumption about relative death rates for disabled, missing deaths will be higher for 1922-31 cohorts than 1932-41 cohorts over a much wider range of assumptions. 
Table 7: Probit Analysis of Mortality Rates in New vs. Old Systems (change in probability of dying by 2002 in percentage points)

Probit regression, reporting marginal effects in percentage points

\begin{tabular}{|l|c|c|c|c|}
\hline & \multicolumn{2}{|l|}{ Men + women } & \multicolumn{2}{l|}{ Men only } \\
\hline & $\mathrm{dF} / \mathrm{dx}$ & $\mathrm{z}$ & $\mathrm{dF} / \mathrm{dx}$ & $\mathrm{z}$ \\
\hline Age-2002 & .06 & $2.65^{*}$ & 0.06 & 1.58 \\
\hline Yrs ed & -.14 & $-3.38^{*}$ & -0.27 & $-4.01^{*}$ \\
\hline female & -2.22 & $-6.06^{*}$ & & \\
\hline Disability & 9.02 & $2.08^{* *}$ & 16.56 & $2.4^{* *}$ \\
\hline Dis86-9 & -2.65 & $-2.03^{* *}$ & -3.81 & $-2.09^{* *}$ \\
\hline Dis90-3 & 7.6 & 1.15 & 13.43 & 1.33 \\
\hline Dis94-7 & -2.1 & -1.24 & -3.26 & -1.48 \\
\hline Dis98-2 & 6.11 & 1.5 & 5.06 & 1.03 \\
\hline New sys & -3.73 & $-7.08^{*}$ & -5.10 & $-6.07^{*}$ \\
\hline Dis*newsys & 12.78 & $3.15^{*}$ & 17.79 & $3.06^{*}$ \\
\hline \# obs & 7674 & & 4429 & \\
\hline Pseudo R2 & .085 & & .078 & \\
\hline Prob>chi2 & 0.00 & & .00 & \\
\hline Obs P & 3.47 & & 4.54 & \\
\hline $\begin{array}{l}\text { Pred P (at } \\
\text { x-bar) }\end{array}$ & 2.58 & & 3.63 & \\
\hline
\end{tabular}

$\mathrm{dF} / \mathrm{dx}$ is for discrete change of dummy variable from 0 to 1

$\mathrm{Z}$ and $\mathrm{P}>|\mathrm{z}|$ correspond to the test of the underlying coefficient being 0

$*=$ significance level $<1 \%$

$* *$ = significance level $>1 \%$ and $<5 \%$

Dis86-9 = started disability pension $1986-89$ or after, relative to $1982-85$

Dis90-3 = incremental effect of starting disability pension 1990-93 or after; $t$ his is added to Dis86-9 to get total effect for 1990-93. And so on.

New sys $=$ new system affiliate

Dis*newsys $=$ disability pensioner in new system 
Table 8: Estimates of Determinants of Hazard of Death after Disability Pension

(Cox Proportional Hazard Model; hazard ratios relative to old-system baseline)

\begin{tabular}{|c|c|c|}
\hline $\begin{array}{c}\text { Covariate: Segment of the } \\
\text { hazard over which effect applies }\end{array}$ & $\begin{array}{c}\text { 1932-62 cohorts } \\
\text { Full Sample } \\
\text { Baseline Differs by Sex }\end{array}$ & $\begin{array}{c}\text { 1932-62 } \text { cohorts }^{\mathrm{a}} \\
\text { Men Only }\end{array}$ \\
\hline $\begin{array}{c}\text { New System: 1-3 years after } \\
\text { pension }\end{array}$ & $\begin{array}{c}72 \\
(-0.40)\end{array}$ & $\begin{array}{c}1.04 \\
(0.04)\end{array}$ \\
\hline $\begin{array}{c}\text { 4-7 years after } \\
\text { pension }\end{array}$ & 10.21 & 7.82 \\
$(2.07)^{* *}$ & $(1.78)^{* * *}$ \\
\hline $\begin{array}{c}\text { 8-15 years after } \\
\text { pension }\end{array}$ & 6.75 & 6.75 \\
$(1.90)^{* * *}$ & \\
\hline \#obs & & 120 \\
\hline
\end{tabular}

* $\quad$ significant at $1 \%$ level or less

** significant at greater than $1 \%$ but less than $5 \%$ level

*** marginally significant at less than $10 \%$ level

Numbers in parentheses are z-statistics.

${ }^{a}$ for group that started pension 1982 or afterwards 
Figure 1: Kaplan-Meier survival as non-disability-pensioner, by system

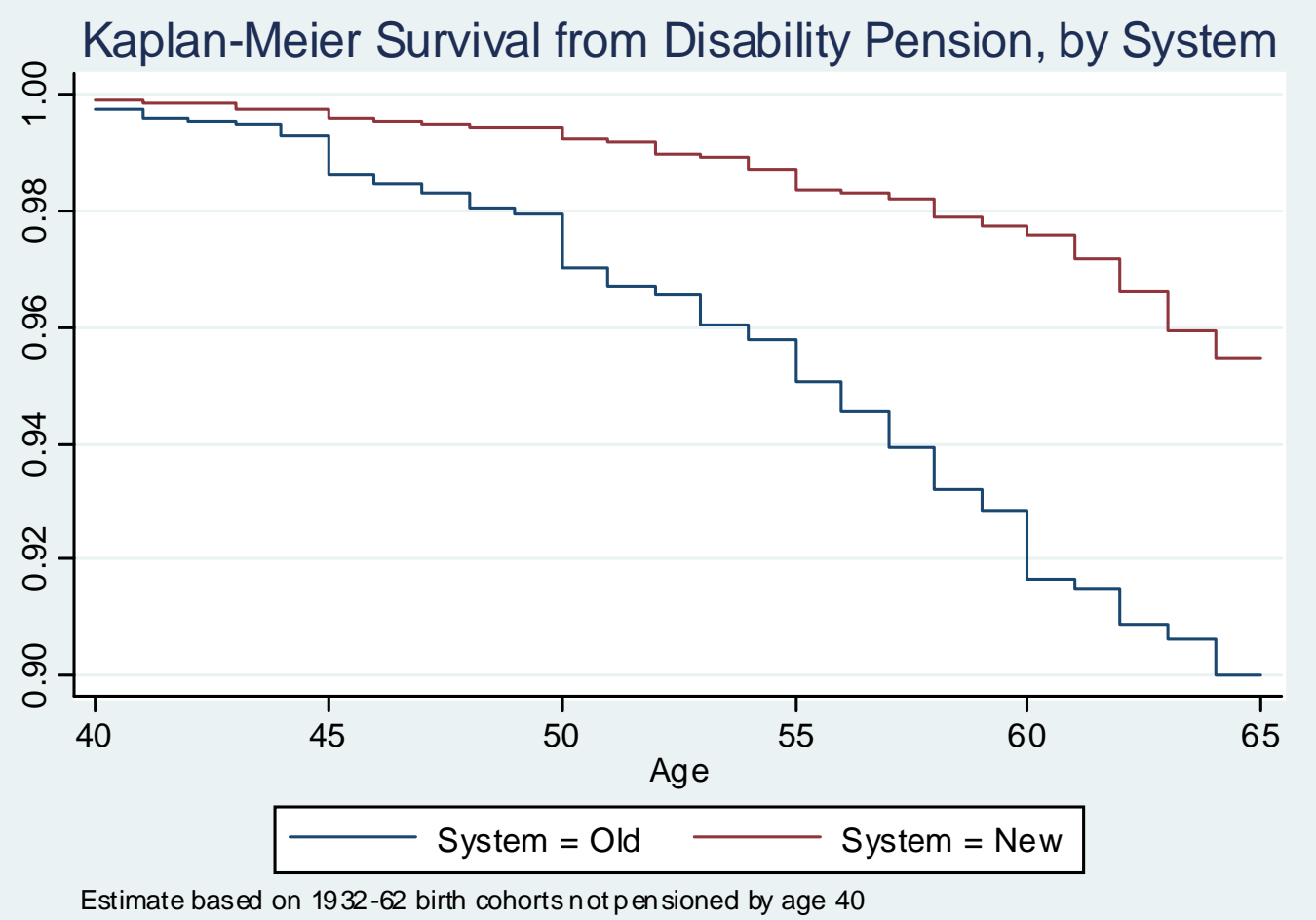

Figure 2: Baseline disability hazards by gender and marital status

Disability Baseline Hazards - Cox Model getting disability pension AT a given age as $\%$ of group at risk

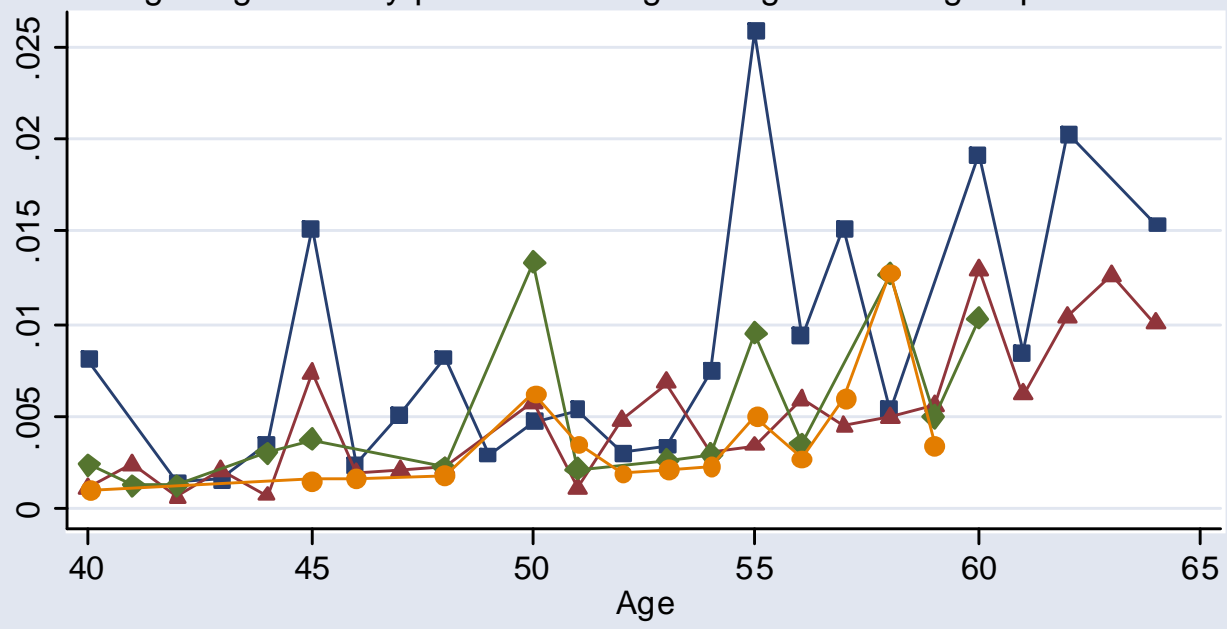

$\longrightarrow$ Single Men $\longrightarrow$ Married Men

Single Women Married Women

Estimate based on 1932-62 birth coh orts not pensioned by age 40 
Figure 3: New vs. old system disability hazards for married men

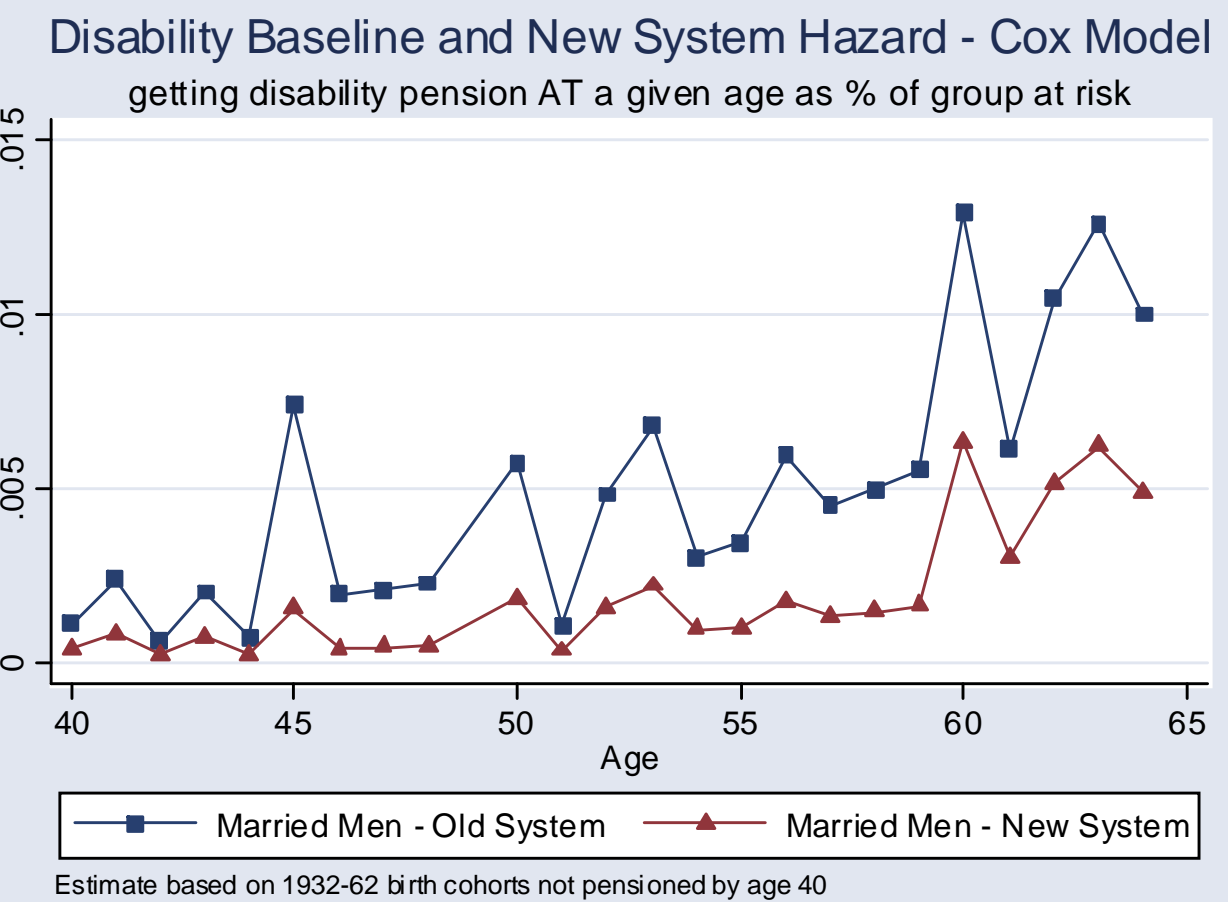

Figure 4: Survival as non-disability pensioner, married men—Cox model

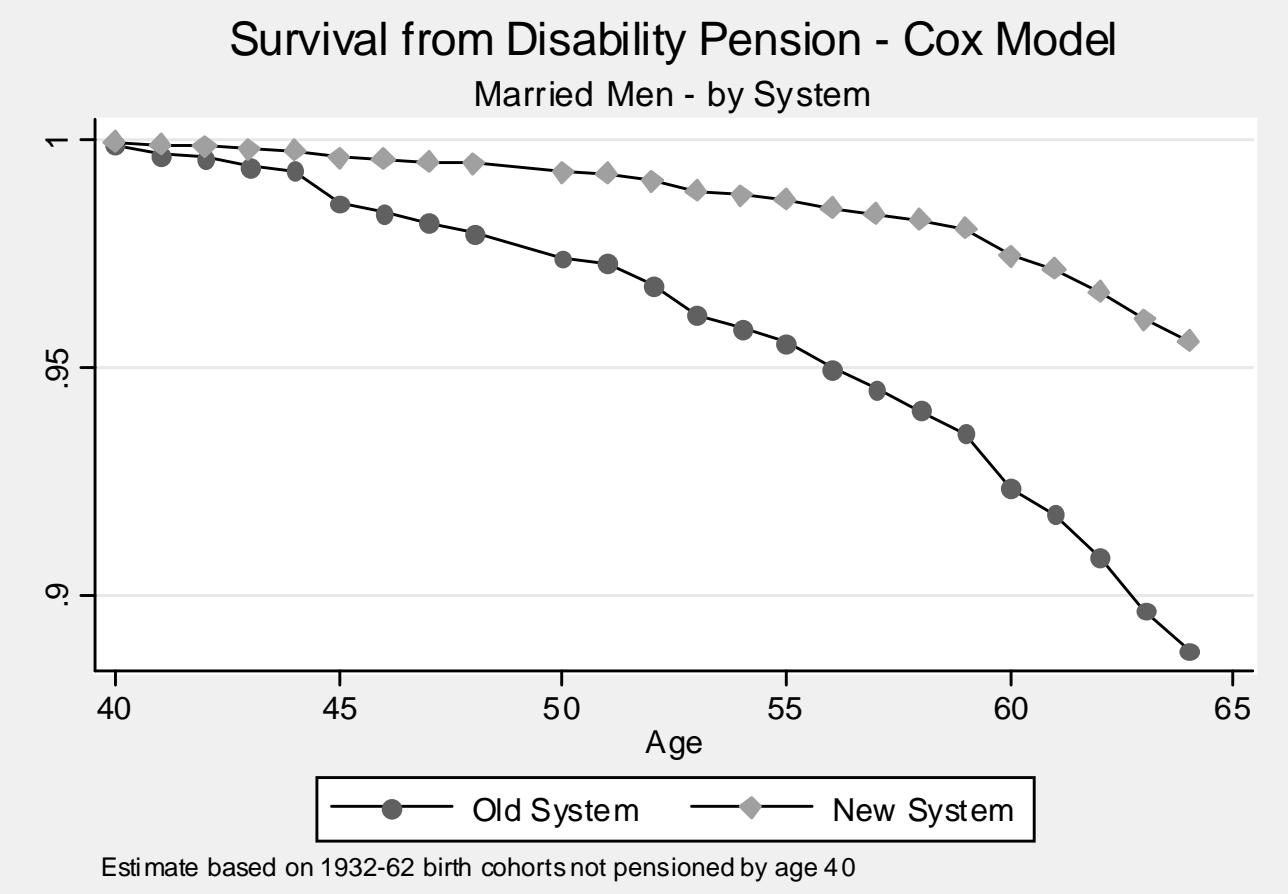


Figure 5: Kaplan-Meier: Survival rates (not dying) by disability status and system

Kaplan-Meier Survival by Disability and System

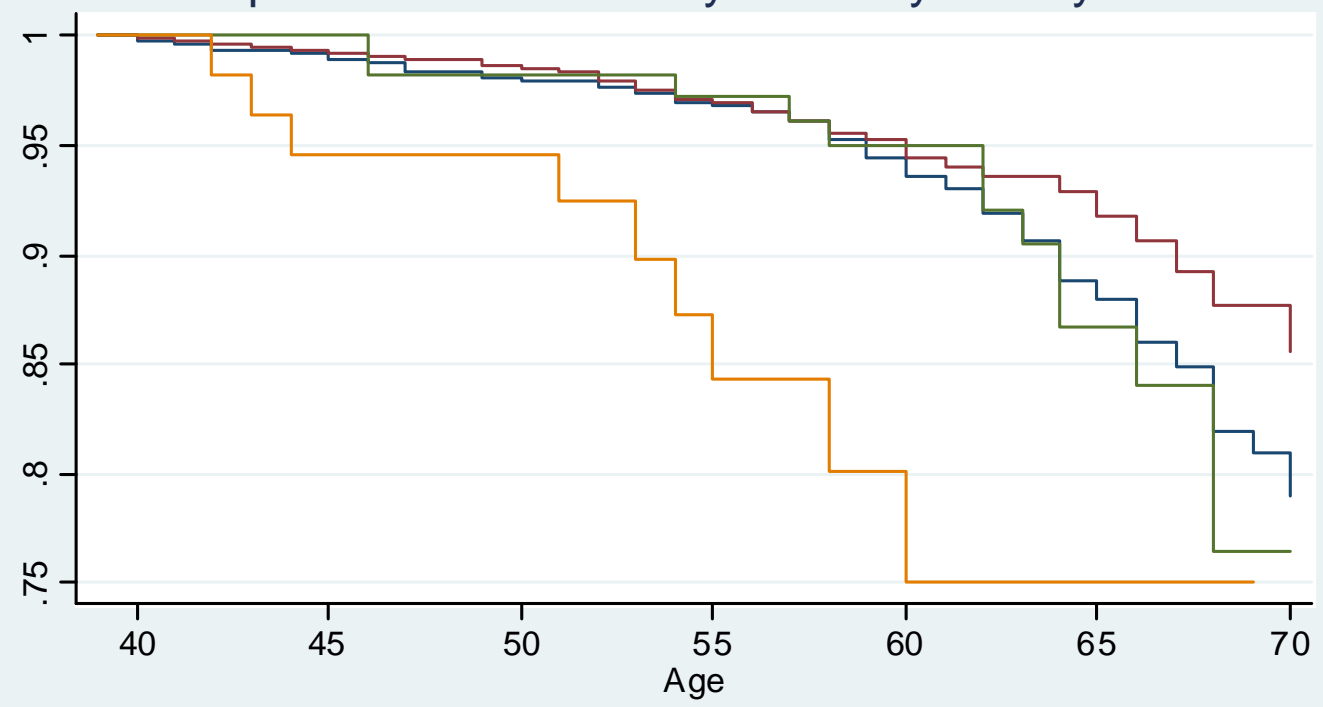

Non Disable-Old System Disable-Old System

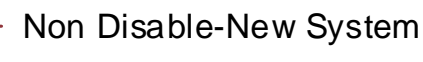
Disable-New System

Estimate based on 1932-62 birth cohorts not pensioned by age 40

Figure 6: Death hazard among disability pensioners, by system

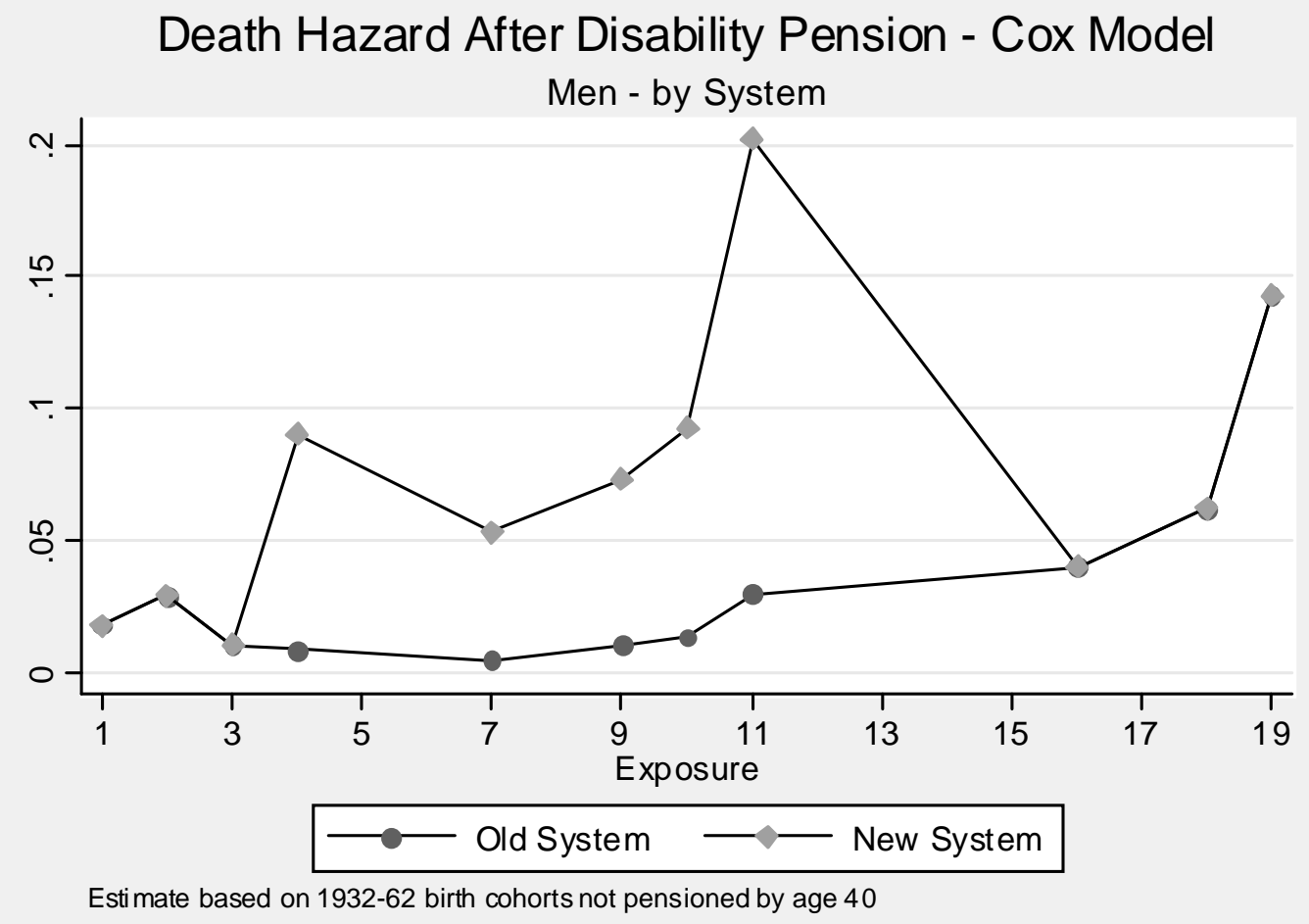


Figure 7: Survival rates among disability pensioners, by system

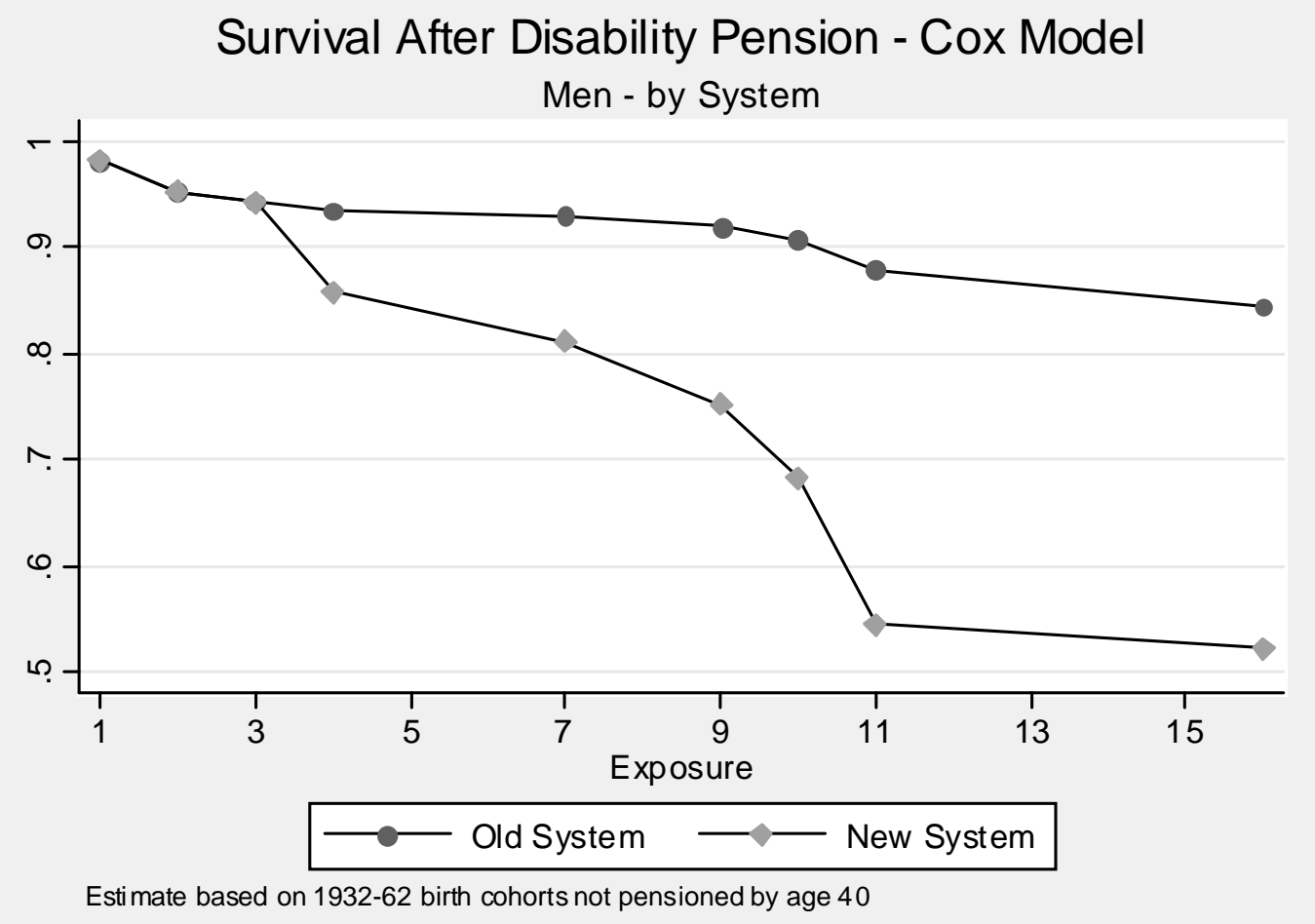




\section{Bibliography}

AIOS. 2005. Boletin Estadistico AIOS. Numero 13. www.aiosfp.org

Andrews, Emily. 1999. "Disability Insurance: Programs and Practice." Social Protection Discussion Paper. Washington DC: World Bank.

Arenas de Mesa, Alberto, Jere Behrman and David Bravo. 2004. "Characteristics of and Determinants of the Density of Contributions in a Private Social Security System". MRRC Working Paper 2004-077.

Arenas de Mesa, Alberto, David Bravo, Jere Behrman, Ollivia Mitchell, Petra Todd. 2007. "The Chilean Pension Reform Turns 25: Lessons from the Social Protection Survey." in Lessons from Pension Reform in the Americas, eds. Stephen. Kay and Tapen Sinha. Oxford University Press.

Association of AFPs. 2004, 2005 and 2006. Sistema de Calificacion de Invalidez: Informe Estadistico. Santiago, Chile.

Autor, David and Mark Duggan. 2006. "The Growth in the Social Security Disability Rolls: A Fiscal Crisis Unfolding." Journal of Economic Perspectives. 20(3): 71-96

Autor, David and Mark Duggan. 2003. "The Rise in the disability Rolls and the Decline in Unemployment." Quarterly Journal of Economics. 118(1): 157-205.

Berstein, Solange, Guillermo Larrain and Francisco Pino. 2006. "Chilean Pension Reform: Coverage Facts and Policy Alternatives.” Journal Economia. 6 (2)

Castro, Ruben. 2005. "Seguro de invalidez y sobrevivencia: que es y que le esta pasando?” Working Paper No5. Superintendencia de AFP. Santiago, Chile.

Duggan, Mark and Scott Imberman. 2006. "Why are the Disability Rolls Skyrocketing?" in Health in Older Ages: The Causes and Consequences of Declining Disability among the Elderly. Eds. David Cutler and David Wise. Chicago: University of Chicago Press.

Edwards, Alejandra and Estelle James. 2006. "Crowd-out, Adverse Selection and Information in Annuity Markets: Evidence from a New Retrospective Data Set in Chile." MRRC Working Paper 2006-147 (UM06-19). Ann Arbor MI.

Edwards, Alejandra and Estelle James. 2005. "Do Individual Accounts Postpone Retirement?: Evidence from Chile.” MRRC Working Paper 2005-098. Ann Arbor, MI.

Gruber, Jonathan. 2000. "Disability Insurance Benefits and Labor Supply." Journal of Political Economy. 108(6). 1162-83.

Grushka, Carlos and Gustavo Demarco. 2003. "Disability Pensions and Social Security Reform Analysis of the Latin American Experience." Social Protection Discussion Paper 0325. Washington DC: World Bank. 
Intsituto de Normalización Previsional.(INP). Anuario Estadistico, 2006. Santiago, Chile. www.inp.cl/portal/inicio/index.jsp

James, Estelle, Guillermo Martinez and Augusto Iglesias. 2006. "The Payout Stage in Chile: Who Annuitizes and Why?" Journal of Pension Economics and Finance. 5(2).

James, Estelle and Augusto Iglesias. 2006. "How to Integrate Disability Benefits into a System with Individual Account.” WP2006-111 (UM05-13). University of Michigan Retirement Research Consortium.

OECD. 2003. Transforming Disability into Ability. Paris: OECD Press.

Rupp, Kalman and David Stapleton. 1995. "Determinants of the Growth in the Social Security Administration's Disability Programs-An Overview." Social Security Bulletin. $58(4)$.

Rupp, Kalman and David Stapleton eds. 1998. Growth in Disability Benefits. Kalamazoo, MI: W.E. Upjohn Institute for Employment Research.

Superintendencia of Pension Fund Administrators (SAFP) 2003. The Chilean Pension System. $4^{\text {th }}$ ed. Santiago, Chile.

U.S. Social Security Advisory Board. 2001. "Charting the Future of Social Security's Disability Programs: The Need for Fundamental Change." Washington DC.

U.S. Social Security Board of Trustees. 2005. Annual Report. Washington DC.

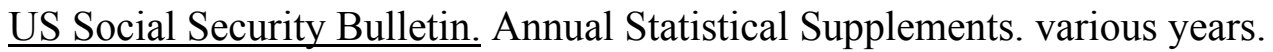

Valdes Prieto, Salvador and Eduardo Navarro Beltran. 1992. "Subsidios Cruzados en el Seguro de Invalidez y Sobrevivencia del Nuevo Sistema Previsional Chileno." Cuadernos de Economia, 29 (88), 409-441.

Von Wachter, Till, Jae Song and Joyce Manchester. 2007. "Changes in the Economic Outcomes of Allowed and Denied Applicants to Social Security Disability Insurance from 1978 to 2004: An Analysis Using Longitudinal Administrative Records.” Draft.

Wiese, Patrick. 2006. "Financing Disability Benefits in a System of Individual Accounts: Lessons from International Experience.” Draft. Urban Institute. 


\section{Footnotes}

${ }^{1}$ For previous discussions of disability insurance in Chile and other countries with individual accounts see Grushka and Demarco 2003, Castro 2004, Wiese 2005, Valdes and Navarro 1992.

2 Annuities last the entire lifetime, thereby providing longevity insurance. Programmed withdrawals have the same expected present value as annuities. They do not provide longevity insurance but do give the worker bequest rights over any money left in the account after he dies. Currently, $40 \%$ of disabled pensioners have annuitized. For more on payout modes see James, Martinez and Iglesias 2006, Edwards and James 2006.

${ }^{3}$ In the U.S., appeals can only be brought by workers whose initial claims have been denied, so appeals inevitably increase approved cases. This is exacerbated by the growing tendency of attorneys who specialize in disability cases to represent applicants in appeals. In 2000 , only $38 \%$ of claims were approved initially, but the majority of those denied benefits appealed and more than half of all appeals eventually won. Therefore, $55 \%$ of all claims were eventually accepted. (Social Security Advisory Board 2001, pp. 8, 18, 19; Autor and Duggan 2006).

${ }^{4}$ For example, a worker approaching age 65 who contributed for only the last ten years and earned a $5 \%$ rate of return would get a replacement rate of only $10 \%$ from his old age pension, but he would get $70 \%$ if he can qualify for a disability benefit.

5 The individual must 1) be working and contributing at the time of the claim, or 2) have contributed during the last 12 months and also paid at least 6 contributions in the year immediately preceding the last registered contribution. 3) Self-employed workers must have paid at least one contribution in the calendar month before the date of the claim. 4) In addition, he must not be a pensioner or be over the normal retirement age $(65 \mathrm{M} / 60 \mathrm{~W})$. Workers who are certified as permanently disabled based on medical criteria but who do not meet these conditions can withdraw their own money as an annuity or programmed withdrawal. But they do not get the additional payment that would cover a $70 \%$ replacement rate - which would raise costs for others.

These conditions are lighter than those in other countries with contributory schemes. For example, 3 years of contributions are typically required in Latin America, 5 years in OECD countries (OECD 2003, Grushka and Demarco 2003, Andrews 1999). In the US the applicant must have worked in 5 of the last 10 years and cannot be working currently.

${ }^{6}$ For workers who have not been in the social security system for ten years, only their membership period is included, with a minimum of 24 months.

${ }^{7}$ This de facto $42 \%$ replacement rate is comparable with the disability replacement rate in many OECD countries, although lower than in the Netherlands or Sweden and higher than the US or UK. See Andrews 1999 and U.S. Social Security Advisory Board 2001 for numbers in other countries. The $70 \%$ replacement rate given to steady workers is unusually high. The definition of the reference wage creates disparities among individuals that may be regarded as questionable. An individual who worked steadily for 
twenty years, then intermittently for ten years, has a larger own-account but gets a lower disability pension than one who worked intermittently for twenty years, then steadily for ten years, assuming that they both have the same age and wage when working.

${ }^{8}$ Calculations by authors based on Association of AFPs, 2004-6. We assume that the future disposition at the second stage of claims that originated in 2004-06 will follow the same pattern as the disposition in 2004-06 of second stage claims. That is, the proportion of second stage claims rejected or deemed ineligible for insurance in 2004-06 is assumed to predict the eventual rejection and eligibility at the second stage of claims that originated at the first stage in 2004-06; and the ratio of second stage claims in 2004-06 to approved first stage claims in 2001-03 is assumed to predict the proportion of approved first stage claims in 2004-06 that will eventually be considered at the second stage. About $30 \%$ of approved first stage claims from 2001-03 were lost due to death, improvement, reaching retirement age before 2004-06, or drop-outs as applicants learned they were ineligible for insurance and/or had small pensions.

9 To be eligible for the MPG, the disabled worker must have: 1) at least 10 years' contributions in the social security system, or 2) at least two years' contributions in the last 5 years prior to the disability claim, or 3) 16 months contributions if he has joined the labor force within the last 2 years, or 4 ) been contributing at the date of disability, if this was caused by an accident. If the individual has other sources of income this may invalidate his eligibility for the MPG. However, we don't know if this means-test is enforced.

${ }^{10}$ For example, disability may be concentrated in groups that tend to be ineligible for insurance in Chile, while other countries have more inclusive coverage. Some countries pay disability benefits with less than $50 \%$ impairment and do not have separate programs for occupational accidents and illness, which would increase their incidence rates. Mature PAYG systems have a large stock of disabled pensioners remaining from past systems, who must be paid, even if the current system has been reformed. These factors would all reduce relative incidence and/or costs in Chile.

However, differences also work in the opposite direction-for example, Chile does not apply a work test while many other countries do; this should increase Chile's relative disability rate. Chile pays disability benefits until death while in some other countries, such as the US, disability benefits are paid only until normal retirement age, at which point old age benefits take over; this should greatly increase Chile's relative cost. In Chile disability benefits are price-indexed, while in some countries only a nominal benefit is specified (less expensive) and, conversely, in other countries benefits are indexed to wages (more expensive).

11 The survey tells us if new system affiliates in 2002 had previously belonged to the old system, but it does not record years of switching. We know from other sources that most switching occurred between 1982 and 1985. For purposes of this analysis, we assume that all switching took place in 1982. The survey also doesn't distinguish between the partially versus fully disabled or between disabled pensioners with or without insurance. 
12 The old-system benefit formula also favored older workers or those who had contributed in the distant past, while the new-system benefit favored younger workers who contributed in the recent past. According to the benefit formula in the largest old system, the SSS, disability benefits were "equal to the retirement pension". The retirement pension, in turn, was based on number of working years- $50 \%$ for first ten years $+1 \%$ for every year after ten up to $70 \%$. This old system formula is more generous for workers who have 30 years of service but have not contributed regularly during the past ten years, while the new system formula is more generous for workers who have less than 30 years of contributions but have contributed regularly during the past ten years. Neither system had a clear-cut advantage here.

In our sample, observed disability pensions in 2002 were $70 \%$ of non-disability pensions, both for the new and old systems. For men, the ratio was $65 \%$ in the new system, $62 \%$ in the old system. Again, no clear-cut difference. Over-all, there is little reason to believe that changes in relative size of disability pension could account for the observed difference in hazard rates.

${ }^{13}$ We checked for the possibility of differences in new-system effects between switchers and non-switchers, and found no significant difference.

${ }^{14}$ Von Wachter et al 2007 show that mortality rates 10 years after pensioning are 3 times higher for disabled pensioners than for those denied disability status in the U.S. for ages $35-55(30 \%$ vs. $10 \%)$.

${ }^{15}$ For the cohorts that were born in 1922, 32 and 42, expected deaths by 2002 are $35 \%$, $15 \%$ and $7 \%$ of those alive in 1982, respectively. Therefore, taking the cohorts born 1922-31 as a group, we would expect that about $25 \%$ of those alive in 1982 would be dead by 2002 , while for cohorts born 1932-41, about $11 \%$ would be dead. However, when we examined our data, we found that only $21 \%$ of affiliates in the cohorts born 1922-31 and 9\% of affiliates in cohorts born 1932-41 who were alive in 1982 were dead by 2002 . In other words, reported deaths relative to expected deaths (R/E ratios) were only $82-84 \%$ for affiliates in these cohort groups.

For disabled pensioners, $35 \%$ of those in the $1922-31$ cohorts and $15 \%$ of those in the 1932-41 cohorts were reported dead by 2002. Their R/E ratios depend on their expected mortality rates, which we don't know. Von Wachter et al 2007 report ten-year death rates 3 times as high for the disabled as the non-disabled in the U.S. But we are measuring mortality from 1982 on, and disabled pensioners were not disabled for this entire period. If their expected mortality rates over this period are $50 \%$ greater than those for affiliates as a whole, reported $=$ expected and there are no missing deaths among the disabled. But if mortality rates among disabled pensioners are twice as high as for affiliates as a whole, their $\mathrm{R} / \mathrm{E}$ ratios are $68-70 \%$. In that case, the proportionate understatement of reported relative to expected deaths is similar for both groups of cohorts. However, this translates into a larger number of missing deaths - $15 \%$ versus $7 \%$ of those alive in 1982--for the 1922-31 compared with the 1932-41 cohorts, since the reported deaths are much higher for the former, who are older. 
${ }^{16}$ For the 1922 cohort, $7 \%$ of affiliates alive in 1962 at age 40 would have died before 1982 , according to RV98. If the disabled death rate was twice as large, this would imply a death rate of $14 \%$ to workers from this cohort who became disabled in 1962 . They disappeared from the sample frame, while the others remained in the sample. Then, the proportion of disabled in the 1922 cohort who died before 1982 and were therefore lost to the sample frame, as a percentage of the reported disabled from this cohort still alive in 1982 , was about $16 \%$. In contrast, using this same methodology, only $4 \%$ of the reported disabled are estimated to have been lost to the sample frame in the 1932 cohort.

${ }^{17}$ The ratio of stock of disabled pensioners to old age pensioners was $30 \%$ in the old system in 2005 but only one-third of that--10\%--in the new system (in 2003) (INP 2006 and SAFP 2003). Since maturity is reached among disability pensioners sooner than among old age pensioners, this ratio will probably fall further for the new system in the future; this is especially the case since new system affiliates have been postponing their age of retirement (Edwards and James 2005). The steady-state stock of disabled relative to old age pensioners in the new system will probably be about one-quarter that in the old system, consistent with our estimated hazard rates.

${ }^{18}$ We only include individuals who pensioned after 1982 in this analysis, because if they pensioned and died before 1982 they would not be included in the ESP sample frame. Therefore, those who switched in 1982 are not included in the old-system analysis.

19 Between 1995 and 2004, the percentage of permanent disabilities accounted for by psychiatric disorders increased from 12 to $20 \%$ of the total in Chile, while cardiac disorders moved in the opposite direction by the same magnitude-from $19 \%$ to $12 \%$. Data provided by Association of AFP's. A similar change occurred in the US and other countries. In 1985 the 4-year mortality rate in the US for disability pensioners as a whole was $22 \%$, but for mental disorders it was only 5\% (Duggan and Imberman 2005).

20 To proxy years of exposure, we include 4 dummy variables interacted with disability pensioner status, indicating the years when the disability pension started: 1986-89, 199093, 1994-97 and 1998-2002, with 1982-85 as the omitted period. We expect a negative sign (fewer deaths) for later periods because they indicate fewer years of exposure to disability status. These dummy interactions measure marginal effects. (That is, the first dummy measures the reduced mortality for all years after 1985 relative to omitted years 1982-85, and the second dummy measures the incremental impact for all years after 1989 , etc.) The first term turns out to be negative and highly significant; those who pensioned after 1986 are less likely to have died by 2002. However, the coefficients on the subsequent dummies are insignificant—no further incremental distinctions after 1986. This suggests an offset by survival bias - dead people are less likely to be lost for later periods - or by the increasing share of new-system disability pensioners in later years. 